\title{
CONTRIBUIÇÃO DOS ISÓTOPOS NATURAIS DE URÂNIO NO ESTUDO DA MOVIMENTAÇÃO DAS ÁGUAS SUBTERRÂNEAS
}

\author{
Luís Henrique MANCINI
}

Daniel Marcos BONOTTO

\begin{abstract}
RESUMO
O urânio é um elemento litófilo, concentrando-se preferencialmente nas rochas ígneas ácidas ao invés das básicas/ultrabásicas. Sua abundância crustal média corresponde a $2,5 \mu \mathrm{g} / \mathrm{g}$, possuindo dois isótopos primários, o ${ }^{238} \mathrm{U}(\sim 99,3 \%)$ e o o ${ }^{235} \mathrm{U}(\sim 0,7 \%)$. Apesar da importância tecnológica do ${ }^{235} \mathrm{U}$, por ser o isótopo físsil que forma a base de produção de energia nuclear, verifica-se que a sua contribuição como fonte natural de radioatividade é pequena, pois a atividade específica do ${ }^{238} \mathrm{U}$ é cerca de 20 vezes maior que a do ${ }^{235} \mathrm{U}$. Os isótopos ${ }^{238} \mathrm{U}$ e ${ }^{235} \mathrm{U}$ são geradores de séries de decaimento radioativo, possuindo o ${ }^{238} \mathrm{U}$ um número maior de descendentes, muitos dos quais de longa meia-vida, como é o caso do ${ }^{234} \mathrm{U}$, que é formado na série do ${ }^{238} \mathrm{U}$ a partir da seguinte sequência: ${ }^{238} \mathrm{U}(4,49 \mathrm{Ga}, \alpha) \rightarrow{ }^{234} \mathrm{Th}(24,1$ dias, $\beta-) \rightarrow{ }^{234} \mathrm{~Pa}(1,18 \mathrm{~min}, \beta-) \rightarrow{ }^{234} \mathrm{U}(248 \mathrm{ka}, \alpha)$ $\rightarrow \ldots$ Tanto ${ }^{238} \mathrm{U}$ quanto ${ }^{234} \mathrm{U}$ são emissores de partículas alfa e, nas águas subterrâneas, a avaliação da extensão do desequilíbrio radioativo entre esses isótopos de urânio, a partir da década de 1960, tem permitido o desenvolvimento de inúmeras pesquisas de interesse hidrogeológico. Os mecanismos principais que explicam esse desequilíbrio são a lixiviação seletiva de ${ }^{234} \mathrm{U}$ em relação a ${ }^{238} \mathrm{U}$ no retículo cristalino dos minerais e o processo de recuo alfa que introduz ${ }^{234} \mathrm{Th}$ na fase líquida, o qual decai por emissão beta para ${ }^{234} \mathrm{~Pa}$ e este para ${ }^{234} \mathrm{U}$, também por emissão beta, ocasionando enriquecimento de ${ }^{234} \mathrm{U}$ nas águas subterrâneas, isto é, razões de atividade ${ }^{234} \mathrm{U} /{ }^{238} \mathrm{U}$ superiores à unidade. Essas razões, juntamente com a concentração do urânio dissolvido, têm sido consideravelmente utilizadas em aplicações hidrológicas, como será descrito neste trabalho.
\end{abstract}

Palavras-chave: Isótopos de urânio; U-238 e U-234; Águas subterrâneas; Datação; Mistura.

\section{ABSTRACT}

CONTRIBUTION OF NATURAL URANIUM ISOTOPES TO THE STUDY OF GROUNDWATER FLOW. Uranium is a lithophile element that is preferentially concentrated in acid rather than basic/ultrabasic igneous rocks. Its average crustal abundance corresponds to $2.5 \mu \mathrm{g} / \mathrm{g}$, composed of two primary isotopes, ${ }^{238} \mathrm{U}(\sim 99.3 \%)$ and ${ }^{235} \mathrm{U}(\sim 0.7 \%)$. Despite the technological importance of ${ }^{235} \mathrm{U}$, as it is the fissile isotope that is the basis of nuclear energy production, it appears that its contribution as a natural source of radioactivity is small, since the specific activity of ${ }^{238} \mathrm{U}$ is about 20 times greater than ${ }^{235} \mathrm{U}$. Isotopes ${ }^{238} \mathrm{U}$ and ${ }^{235} \mathrm{U}$ are progenitors of radioactive decay series, the greater number of descendants corresponding to ${ }^{238} \mathrm{U}$, many of which possessing a long half-life, such as ${ }^{234} \mathrm{U}$ formed in the ${ }^{238} \mathrm{U}$ decay series from the following sequence: ${ }^{238} \mathrm{U}$ $(4.49 \mathrm{Ga}, \alpha) \rightarrow{ }^{234} \mathrm{Th}(24.1$ days, $\beta-) \rightarrow{ }^{234} \mathrm{~Pa}(1.18 \mathrm{~min}, \beta-) \rightarrow{ }^{234} \mathrm{U}(248 \mathrm{ka}, \alpha) \rightarrow \ldots$ Both ${ }^{238} \mathrm{U}$ and ${ }^{234} \mathrm{U}$ are emitters of alpha particles and, in groundwater, the assessment of the extent of radioactive imbalance between these uranium isotopes has allowed the development of numerous studies of hydrogeological interest since the 1960's. The main mechanisms that explain such disequilibrium are the ${ }^{234} \mathrm{U}$ selective leaching relatively to ${ }^{238} \mathrm{U}$ from the crystalline lattice of minerals and alpha recoil that introduces ${ }^{234} \mathrm{Th}$ into the liquid phase, which forms ${ }^{234} \mathrm{~Pa}$ by beta decay, radionuclide that produces ${ }^{234} \mathrm{U}$, also 
by beta decay, causing ${ }^{234} \mathrm{U}$-enrichment in groundwaters, i.e., ${ }^{234} \mathrm{U} /{ }^{238} \mathrm{U}$ activity ratios greater than unity. These ratios, together with the dissolved uranium concentration, have been extensively utilized in hydrological applications, such as those described in this paper.

Keywords: Uranium isotopes; U-238 and U-234; Groundwater; Dating; Mixing.

\section{INTRODUÇÃO}

A descoberta do urânio ocorreu em 1789, quando o químico analítico M. H. Klaproth estudava pechblenda, sendo o novo elemento inicialmente designado de uranit em homenagem ao planeta Uranus e depois uranium. Contudo, foi somente após 1896, com a descoberta da radioatividade por Becquerel e pelo casal Pierre Curie e Marie Curie, que se tornou possível averiguar que esse elemento é progenitor de outros igualmente radioativos, identificados no início do século XX, tais como o uranium II ou a emanation, sob a forma gasosa, bastante utilizada por Rutherford em seus experimentos (CHERDYNTSEV 1969). Hoje sabe-se que aquelas designações correspondem ao ${ }^{238} \mathrm{U}$, ${ }^{234} \mathrm{Ue} \mathrm{e}^{222} \mathrm{Rn}$, e que quando Agricola, em 1556, considerou que a morte de muitos mineiros na Europa estava relacionada com o fato de que o "ar pernicioso que eles respiram algumas vezes apodrece os seus pulmões", não é possível ignorar a responsabilidade da contribuição do gás ${ }^{222} \mathrm{Rn}$ naquele episódio.

Com o avanço das pesquisas e a introdução do termo isótopos por Soddy, em 1910, verificou-se que a abundância crustal média do urânio corresponde a $2,5 \mu \mathrm{g} / \mathrm{g}$, possuindo esse elemento dois isótopos primários, o ${ }^{238} \mathrm{U}$ e o ${ }^{235} \mathrm{U}$, os quais ocorrem atualmente na proporção de $99,28 \%$ de ${ }^{238} \mathrm{U}$ para $0,72 \%$ de ${ }^{235} \mathrm{U}$. Exceção a esse padrão geral de abundância foi primeiramente notada na mina Oklo localizada no Gabão, África, tendo COWAN (1976) referido ao valor 0,7171 para a razão isotópica ${ }^{235} \mathrm{U} / 238 \mathrm{U}$, a qual foi atribuída à "destruição" in situ do ${ }^{235} \mathrm{U}$ por processos de fissão. Esses dois isótopos de urânio são emissores de partículas alfa, que correspondem a núcleos de ${ }^{4} \mathrm{He}$ duplamente ionizado, dando origem a duas séries de decaimento radioativo geneticamente independentes. Como a massa atômica modifica-se aproximadamente de 4 unidades no decaimento $\alpha$, permanecendo praticamente inalterada por ocasião do decaimento $\beta$, os vários números de massa encontrados nos membros dessas séries diferem por múltiplos de 4 . Assim, as fórmulas gerais dessas séries são expres- sas por $4 n+2$ (série do urânio, ${ }^{238} \mathrm{U}$ ) e $4 n+3$ (série do actínio, ${ }^{235} \mathrm{U}$ ), onde $n$ é um inteiro que varia de 51 a 59 na série $4 n+2$ e de 51 a 58 na série $4 n+3$ (KU 1976, IVANOVICH \& HARMON 1982). Isótopos estáveis de chumbo são gerados após a sucessão de decaimentos alfa e beta, possuindo o ${ }^{238} \mathrm{U}$ um número maior de produtos de decaimento em relação ao ${ }^{235} \mathrm{U}$, muitos dos quais de longa meia-vida. Nas séries $4 n+2$ e $4 n+3$, os produtos finais gerados correspondem ao ${ }^{206} \mathrm{~Pb}$ e ${ }^{207} \mathrm{~Pb}$, respectivamente (Figura 1).

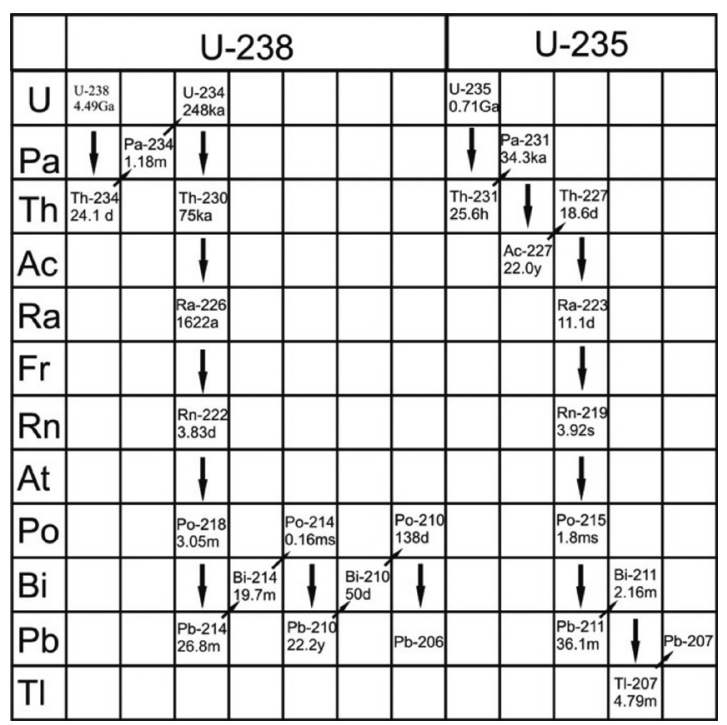

FIGURA 1 - As séries naturais do urânio $(4 n+2)$ e actínio (4n+3). Adaptado de KU (1976).

Juntamente com o ${ }^{238} \mathrm{U}$ e o ${ }^{235} \mathrm{U}$, o ${ }^{234} \mathrm{U}$ constitui o outro isótopo natural de urânio. Este radionuclídeo tem abundância média na crosta de 2 a $3 \times 10^{-}$ ${ }^{80} \%$. O ${ }^{234} \mathrm{U}$ é radiogênico, sendo gerado pelo ${ }^{238} \mathrm{U}$ após o decaimento de dois nuclídeos de meia-vida insignificante na escala de tempo geológico, isto é, o ${ }^{234} \mathrm{Th}$ e o ${ }^{234} \mathrm{~Pa}$, conforme pode-se notar na figura 1. Numa mistura contendo estes isótopos, as proporções relativas de ${ }^{238} \mathrm{U},{ }^{235} \mathrm{U}$ e ${ }^{234} \mathrm{U}$ geralmente correspondem a $99,28 \%, 0,72 \%$ e $0,0054 \%$, respectivamente. No início, ${ }^{234} \mathrm{U}$ foi designado de "uranium 
II, UII, $U_{I I}$ ". Por exemplo, GEIGER \& NUTTALL (1911) descreveram da seguinte maneira o alcance das partículas alfa de uma fonte de urânio, conforme medidas realizadas numa câmara de ionização de Bragg: "Portanto, o Urânio I, com uma meia-vida de $5 \times 10^{9}$ anos, emite partículas alfa que atingem $2,5 \mathrm{~cm}$ no ar à pressão atmosférica $\mathrm{e} 15^{\circ} \mathrm{C}$, ocorrendo, em seguida, a emissão de partículas alfa numa distância de até $2,9 \mathrm{~cm}$ por um novo produto emissor de raios alfa, uranium II, o qual possui meia-vida de $2 \times 10^{6}$ anos". Na realidade, BOLTWOOD (1908) e GEIGER \& RUTHERFORD (1910) já haviam suspeitado da existência de um segundo isótopo natural de urânio emissor alfa, a partir do número de partículas alfa emitidas pelo átomo de urânio. Com base na sistemática nuclear do decaimento do urânio, SODDY (1923) associou o $U_{I I}$ com o ${ }^{234} U$, tendo NIER (1939) demonstrado que o ${ }^{234} \mathrm{U}$ era um constituinte menor do urânio de ocorrência natural, isto é, possuía uma abundância $1 / 17000 \%$ daquela do ${ }^{238} \mathrm{U}$. A meia-vida atualmente adotada para o ${ }^{234} \mathrm{U}$ é de $\sim 248.000$ anos (Figura 1).

Além de sua formação durante o decaimento beta do ${ }^{234} \mathrm{~Pa}$ na série do urânio, $\mathrm{o}{ }^{234} \mathrm{U}$ pode resultar do decaimento alfa do ${ }^{238} \mathrm{Pu}$ (Figura 2a), porém, isto não tem sido verificado até o momento na nature$\mathrm{za}$, apenas em reatores nucleares. $\mathrm{O}{ }^{234} \mathrm{U}$, ao emitir partículas alfa, deixa o núcleo em dois estados excitados: $51,5 \mathrm{keV}$, cuja probabilidade de transição é $28 \%$ e $174 \mathrm{keV}$, com probabilidade de transição de $0,3 \%$ (Figura $2 b$ ).

Estudos pioneiros sobre a presença de ${ }^{234} \mathrm{U}$ na natureza foram conduzidos em 1953 nos laboratórios da Universidade do Cazaquistão em Alma-Ata.
CHERDYNTSEV et al. (1955) publicaram os primeiros resultados de desequilíbrio radioativo entre ${ }^{234} \mathrm{U} \mathrm{e}^{238} \mathrm{U}$ em minerais recém-formados. Os estudos de seu grupo tiveram continuidade e BARANOV et al. (1958) examinaram minerais secundários e redepositados, detectando desequilíbrios tanto nas soluções lixiviadoras quanto nos resíduos lixiviados.

No início, as investigações envolvendo o desequilíbrio radioativo entre os isótopos de urânio ${ }^{234} \mathrm{U}$ e ${ }^{238} \mathrm{U}$ concentraram-se em estudos para possíveis aplicações à geocronologia. THURBER (1962) identificou um valor acentuado de ${ }^{234} \mathrm{U}$ em carbonatos recém-formados nos oceanos (idade ${ }^{14} \mathrm{C}$ menor que 2000 anos para oólitos das Bahamas), tendo sido determinado um excesso de $15 \%$ em relação ao valor esperado envolvendo o equilíbrio radioativo. THURBER (1962) aplicou os resultados de desequilíbrio entre ${ }^{234} \mathrm{U}$ e ${ }^{238} \mathrm{U}$ à datação geocronológica de corais, assumindo que o excesso $\mathrm{de}^{234} \mathrm{U}$ poderia ser aplicado nas datações de minerais até o último milhão de anos, desde que as mudanças nas razões de atividade ocorressem apenas em função do decaimento radioativo.

Os trabalhos sucessivos começaram a descrever possíveis aplicações hidrológicas para a razão de atividade ${ }^{234} \mathrm{U} /{ }^{238} \mathrm{U}$. Os primeiros estudos sistemáticos em um sistema simples de água subterrânea foram efetuados por OSMOND et al. (1968), que sugeriram que a concentração de urânio dissolvido e a razão de atividade ${ }^{234} \mathrm{U} /{ }^{238} \mathrm{U}$ poderiam ser utilizadas como propriedades caracterizadoras do aquífero. Um sumário de alguns resultados divulgados por vários pesquisadores no período de 1963 a 1981 encontra-se representado na tabela 1 . a)

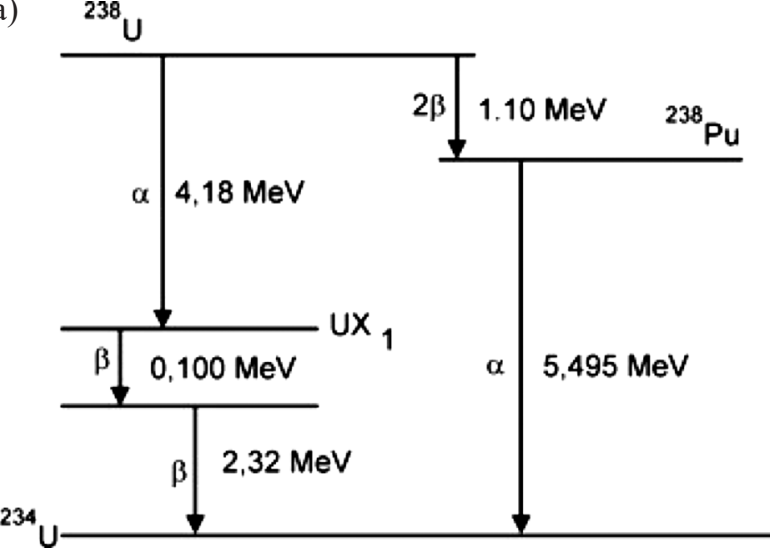

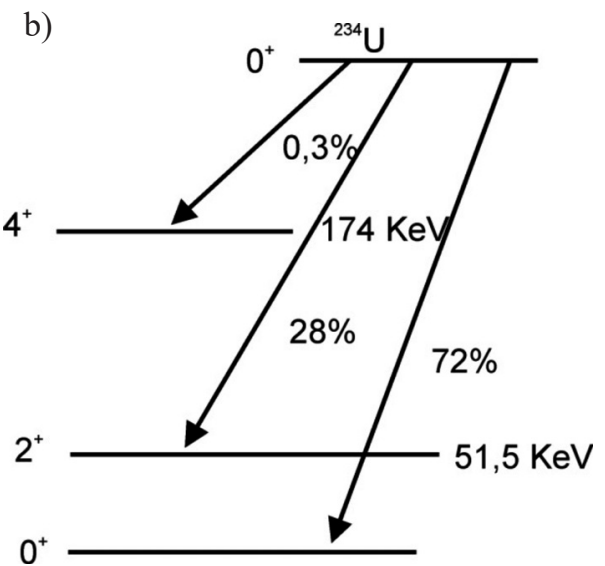

FIGURA 2 - (a) Esquemas de decaimento do ${ }^{238} \mathrm{U}$ e ${ }^{238} \mathrm{Pu}$, com a formação de ${ }^{234} \mathrm{U}$. (b) Esquema de decaimento alfa do ${ }^{234} \mathrm{U}$. Adaptado de CHERDYNTSEV (1969). 
TABELA 1 - Razão de atividade ${ }^{234} \mathrm{U}^{238} \mathrm{U}$ (RA ou AR) divulgada por diferentes pesquisadores entre $1963 \mathrm{e}$ 1981.

\begin{tabular}{|c|c|c|}
\hline Referência & Amostra Analisada & $R A($ ou $A R)$ \\
\hline HILL \& CROOKALL (1963) & água potável inglesa de poço de $\sim 300 \mathrm{~m}$ de profundidade & 2,3 \\
\hline KOIDE \& GOLDBERG (1965) & águas superficiais e profundas de oceanos & 1,14 \\
\hline BLANCHARD (1965) & águas e carapaças de moluscos de regiões costeiras (EUA) & $0,92-1,17$ \\
\hline OSMOND et al. (1965) & corais recentes e do Pleistoceno das regiões costeiras da Flórida (EUA) & $1,08-1,17$ \\
\hline KAUFMAN \& BROECKER (1965) & depósitos carbonatados em lagos (EUA) & $1,28-1,97$ \\
\hline KU (1965) & sedimentos pelágicos oceânicos & $0,78-1,45$ \\
\hline MIYAKE et al. (1966) & águas marinhas superficiais e profundas a norte do Oceano Pacífico & 1,09 \\
\hline MOORE (1967) & águas superficiais do Rio Amazonas (Brasil) & 1,1 \\
\hline MOORE (1967) & águas superficiais do Rio Mississippi (EUA) & 1,31 \\
\hline OSMOND et al. (1968) & águas subterrâneas da Flórida (EUA) & $0,69-1,02$ \\
\hline SCOTT (1968) & sedimentos de rios a leste e sudoeste dos EUA & $0,83-1,28$ \\
\hline SOMAYAJULU \& CHURCH (1973) & $\begin{array}{l}\text { água intersticial da região equatorial do Oceano Pacífico a } 4178 \mathrm{~m} \text { de pro- } \\
\text { fundidade }\end{array}$ & 1,19 \\
\hline KRONFELD (1974) & águas subterrâneas do aquífero Trinity, Texas (EUA) & $0,92-12,25$ \\
\hline COWART \& OSMOND (1974) & águas subterrâneas do aquífero Carrizo, Texas (EUA) & $0,52-9,02$ \\
\hline WARKSHAL \& YARON (1974) & águas subterrâneas a norte de Israel & $1,04-2,81$ \\
\hline KRONFELD et al. (1975) & $\begin{array}{l}\text { águas subterrâneas de } 2000 \mathrm{~m} \text { de profundidade em campos petrolíferos salinos } \\
\text { a norte de Jerusalém }\end{array}$ & $8,6-10,1$ \\
\hline COWART \& OSMOND (1977) & $\begin{array}{l}\text { águas subterrâneas de aquífero no arenito Carrizo e em aquíferos com mine- } \\
\text { ralizações de urânio no Texas (EUA) }\end{array}$ & $0,56-9,02$ \\
\hline GOMES (1978) & águas subterrâneas do aquífero calcário Bambuí, Brasil & $1,75-10,58$ \\
\hline COWART (1980) & águas subterrâneas do aquífero calcário Edwards (EUA) & $0,79-2,66$ \\
\hline CHATAM et al. (1981) & águas subterrâneas de aquífero em arenito no Rio Powder, Wyoming (EUA) & $1,0-14,0$ \\
\hline CHATAM et al. (1981) & águas subterrâneas do aquífero no arenito Oakville, Taxas (EUA) & $0,2-4,0$ \\
\hline
\end{tabular}

\section{FUNDAMENTAÇÃO TEÓRICA}

\subsection{Equilíbrio radioativo secular}

A radioatividade devida ao urânio $\left({ }^{238} \mathrm{U}\right)$ e descendentes em sua cadeia de decaimento pode ser medida a partir da atividade A de cada nuclídeo, definida como a função:

$$
\mathrm{A}=|\mathrm{dN} / \mathrm{dt}|
$$

Nessa expressão, dN/dt é a taxa de variação do número de nuclídeos por unidade de tempo, isto é:

$$
\mathrm{dN} / \mathrm{dt}=-\lambda \mathrm{N}
$$

onde: $\lambda$ é a constante de decaimento, que representa a probabilidade de um nuclídeo desintegrar-se espontaneamente por unidade de tempo (tem dimensão de tempo ${ }^{-1}$ ) e $\mathrm{N}$ é o número de átomos no sistema considerado num tempo t.
A integração da equação (2) fornece:

$$
\mathrm{N}=\mathrm{N}_{0} \exp (-\lambda \mathrm{t})
$$

onde: $\mathrm{N}_{0}$ corresponde ao número de átomos inicialmente do sistema. Se $\mathrm{T}_{1 / 2}$ é o tempo para a desintegração de metade dos átomos do sistema (meia-vida do nuclídeo), então:

$$
\lambda=0,693 / \mathrm{T}_{1 / 2}
$$

Numa amostra de mineral ou rocha portadora de urânio, ocorrerão emissões alfa do ${ }^{238} \mathrm{U}$ de acordo com uma probabilidade $\lambda$ de decaimento, tendo em vista que esse nuclídeo é "pai" da série radioativa do urânio. Os "filhos" originados também sofrem decaimentos sucessivos até que o nuclídeo estável de chumbo ${ }^{206} \mathrm{~Pb}$ é atingido.

$\mathrm{O}$ acúmulo dos produtos de decaimento na série radioativa, para um número muito gran- 
de de átomos, é descrito pelo sistema de equações diferenciais:

$$
\begin{gathered}
\mathrm{dN}_{1}=-\lambda_{1} \mathrm{~N}_{1} \mathrm{dt} \\
\mathrm{dN}_{2}=\left(\lambda_{1} \mathrm{~N}_{1}-\lambda_{2} \mathrm{~N}_{2}\right) \mathrm{dt} \\
\mathrm{dN}_{3}=\left(\lambda_{2} \mathrm{~N}_{2}-\lambda_{3} \mathrm{~N}_{3}\right) \mathrm{dt} \\
\ldots \ldots . \quad \ldots \ldots \ldots \ldots \ldots \ldots . . \\
\mathrm{dN}_{\mathrm{i}}=\left(\lambda_{\mathrm{i}-1} \mathrm{~N}_{\mathrm{i}-1}-\lambda_{\mathrm{i}} \mathrm{N}_{\mathrm{i}}\right) \mathrm{dt}
\end{gathered}
$$

BATEMAN (1910) propôs a solução destas equações. Cada $\mathrm{N}_{\mathrm{i}}$ é o número de átomos do i-ésimo nuclídeo da série radioativa presente no instante $t$ e $\lambda_{\mathrm{i}}$ é a sua respectiva constante de decaimento. Se o índice "o" corresponde ao estado inicial no instante $\mathrm{t}=0$, assumindo $\mathrm{N}_{2}{ }^{0}=0$, a integração da segunda equação de (5) fornece o número de nuclídeos produzidos a partir do decaimento radioativo de um determinado "pai", ou seja:

$$
\mathrm{N}_{2}=\lambda_{1} \mathrm{~N}_{1}^{0}\left[\exp \left(-\lambda_{1} \mathrm{t}\right)-\exp \left(-\lambda_{2} \mathrm{t}\right)\right] /\left(\lambda_{2}-\lambda_{1}\right)
$$

No caso em que $\lambda_{2}>>\lambda_{1}$, pode-se simplificar a expressão para:

$$
\mathrm{N}_{2}=\lambda_{1} \mathrm{~N}_{1}^{0}\left[1-\exp \left(-\lambda_{2} \mathrm{t}\right)\right] / \lambda_{2}
$$

Se o sistema existe há muito tempo $(\mathrm{t} \rightarrow 8$ $\mathrm{T}_{1 / 2}$ ), pode-se escrever:

$$
\mathrm{N}_{2}=\lambda_{1} \mathrm{~N}_{1}^{0} / \lambda_{2}
$$

Nessas condições, $\mathrm{dN}_{2} / \mathrm{dt}=0$ e o número de átomos do produto permanece inalterado. $\mathrm{O}$ conjunto de equações diferenciais (5) será estacionário, valendo as relações:

$$
\begin{gathered}
\mathrm{dN}_{1} / \mathrm{dt}=\lambda_{1} \mathrm{~N}_{1} \\
\mathrm{dN}_{2} / \mathrm{dt}=\left(\lambda_{1} \mathrm{~N}_{1}-\lambda_{2} \mathrm{~N}_{2}\right)=0 \\
\mathrm{dN}_{3} / \mathrm{dt}=\left(\lambda_{2} \mathrm{~N}_{2}-\lambda_{3} \mathrm{~N}_{3}\right)=0 \\
\ldots . \quad \ldots \ldots \ldots \ldots . . \\
\mathrm{dN}_{\mathrm{i}} / \mathrm{dt}=\left(\lambda_{\mathrm{i}-1} \mathrm{~N}_{\mathrm{i}-1}-\lambda_{\mathrm{i}} \mathrm{N}_{\mathrm{i}}\right)=0
\end{gathered}
$$

Pode-se notar que o número de átomos que decaem por unidade de tempo é igual ao número de átomos formados no mesmo intervalo de tempo, situação que ocorre em um sistema fechado para os membros da série radioativa do urânio. Isto constitui o que se denomina de Equilibrio Radioativo Secular, sendo também expresso por:

$$
\lambda_{1} \mathrm{~N}_{1}=\lambda_{2} \mathrm{~N}_{2}=\lambda_{3} \mathrm{~N}_{3}=\ldots . .=\lambda_{\mathrm{i}} \mathrm{N}_{\mathrm{i}}
$$

Portanto, num sistema onde a série do urânio está em Equilíbrio Radioativo Secular, as atividades dos seus produtos de decaimento são iguais entre si. Como a $\lambda$ do ${ }^{238} \mathrm{U}$ é extremamente menor que as de seus "filhos", a equação (7) é uma boa apro- ximação que possibilita determinar o tempo para os nuclídeos de sua cadeia atingirem o equilíbrio radioativo com ele.

Em sistemas fechados, não sujeitos a processos de intemperismo, a condição de Equilíbrio Radioativo Secular é estabelecida para o ${ }^{234} \mathrm{U}$ e o ${ }^{238}$ U. Pela expressão (10) pode-se escrever:

$$
\lambda_{238} \mathrm{~N}_{238}=\lambda_{234} \mathrm{~N}_{2234}
$$

onde o índice 238 refere-se ao isótopo ${ }^{238} \mathrm{U}$ e o índice 234 ao isótopo ${ }^{234} \mathrm{U}$.

Costuma-se designar na literatura de razão de atividade alfa RA (ou AR) à razão entre as atividades A dos isótopos de urânio de números de massa 234 e 238, respectivamente, ou seja:

$$
\mathrm{RA}=\mathrm{A}_{234} / \mathrm{A}_{238}
$$

Aplicando a expressão (11) em (12) obtém-se que RA $=1$ nos sistemas fechados em equilíbrio secular. Como $\lambda_{238}<<\lambda_{234}$, pode-se determinar o tempo para o ${ }^{234} \mathrm{U}$ atingir o equilíbrio radioativo com $\mathrm{O}{ }^{238} \mathrm{U}$, por intermédio da equação (7) modificada:

$$
\mathrm{t}=-\ln \left[1-\lambda_{234} \mathrm{~N}_{2234} / \lambda_{238} \mathrm{~N}_{238}\right] / \lambda_{234}
$$

No equilíbrio $(\mathrm{RA}=1)$, essa equação não apresenta solução. Contudo, considerando-se a razão entre os dois isótopos como sendo 0,99 , pode-se simplificá-la para:

$$
\mathrm{t}=4,61 / \lambda_{234}
$$

Pela substituição do valor de $\lambda_{234}$ conclui-se que num sistema fechado com idade mínima de 1 milhão de anos fica estabelecido o equilíbrio radioativo secular entre o ${ }^{234} \mathrm{U}$ e o ${ }^{238} \mathrm{U}$. Mesmo em sistemas abertos, desvios significantes na RA não são esperados devido a pequena diferença de massa entre os dois isótopos $(1,7 \%)$ e as curtas meias-vidas dos dois "filhos" intermediários. Entretanto, os resultados obtidos por vários pesquisadores não confirmaram isto, tendo sido registradas extremas variações nas atividades de ${ }^{234} \mathrm{U}$ e ${ }^{238} \mathrm{U}$, conduzindo ao desequilíbrio radioativo entre esses isótopos (RA diferente de 1, conforme ilustrado na tabela 1).

KAUFMAN et al. (1969) atribuíram os baixos valores de RA encontrados em aquífero cárstico na Flórida (EUA) a uma possível carência de água no aquífero durante o Pleistoceno, devido ao abaixamento do nível do mar naquela época; posteriormente, teria havido remoção de ${ }^{234} \mathrm{U}$ com início de grandes fluxos de água subterrânea, ficando o aquífero deficiente nesse nuclídeo na época atual. 
KRONFELD et al. (1975) interpretaram os valores altos na razão de atividade ${ }^{234} \mathrm{U} /{ }^{238} \mathrm{U}$ em campos petrolíferos salinos a uma combinação do recuo alfa do ${ }^{234} \mathrm{Th}$ e do longo do tempo de residência de água nos poços estudados.

KRONFELD \& ADAMS (1974), a partir dos dados de RA, avaliaram o padrão geral de circulação de águas subterrâneas em aquífero no arenito Trinity no Texas (EUA), observando uma leve tendência de decréscimo na concentração de urânio com o aumento na RA.

WARKSHAL \& YARON (1974) constataram que a RA aumenta radialmente para fora de área identificada como zona de recarga das águas subterrâneas ao norte de Israel, atribuindo isto às mais novas aberturas, devido às recentes atividades tectônicas ou aos efeitos do clima.

COWART \& OSMOND (1974) observaram que as águas próximas dos afloramentos na zona de recarga de aquífero no arenito Carrizo no Texas (EUA) apresentam concentrações altas de urânio e baixos valores de RA. Nas zonas mais profundas, exibem baixas concentrações de urânio e valores elevados de RA. O efeito foi atribuído à passagem da água de uma zona oxidante para uma redutora, com a formação de frentes de concentração de urânio que agiriam como fontes de enriquecimentos de ${ }^{234} \mathrm{U}$ e seriam responsáveis pela baixa concentração de urânio na água. Com a penetração da água nas zonas ainda mais profundas, os autores observaram um decréscimo na RA, atribuindo-o ao decaimento do ${ }^{234} \mathrm{U}$.

\subsection{Mistura de águas subterrâneas}

A estimativa de proporções de águas subterrâneas de diferentes procedências que contribuem numa mistura constitui uma importante aplicação em hidrogeologia dos isótopos de urânio ${ }^{234} \mathrm{U}$ e ${ }^{238} \mathrm{U}$. A modelagem foi elaborada por OSMOND et al. $(1968,1974)$ que consideraram as águas naturais como um sistema de diluição isotópica no qual as variações da razão ${ }^{234} \mathrm{U} /{ }^{238} \mathrm{U}$ ocorreriam apenas com a adição de urânio, pela lixiviação das rochas circundantes ou da mistura com outras águas contendo urânio; estando o urânio em solução, sua razão de atividade não seria afetada por diluição ou precipitação. Ao se misturar uma água 1 com uma água 2 para produzir uma água $\mathrm{T}$, cada uma com uma concentração C de urânio (em $\mu \mathrm{g} / \mathrm{L}$ ) e razão de atividade ${ }^{234} \mathrm{U} /{ }^{238} \mathrm{U}$, poderiam ser escritas as seguintes relações:

$$
\begin{gathered}
\mathrm{V}_{1}+\mathrm{V}_{2}=\mathrm{V}_{\mathrm{T}} \\
\mathrm{M}_{1}+\mathrm{M}_{2}=\mathrm{M}_{\mathrm{T}} \\
\mathrm{V}_{1}=\mathrm{M}_{1} \mathrm{~S}_{1} \\
\mathrm{M}_{1} \mathrm{~A}_{1}+\mathrm{M}_{2} \mathrm{~A}_{2}=\mathrm{M}_{\mathrm{T}} \mathrm{A}_{\mathrm{T}} \\
\mathrm{M}_{1} \mathrm{~S}_{1}+\mathrm{M}_{2} \mathrm{~S}_{2}=\mathrm{M}_{\mathrm{T}} \mathrm{S}_{\mathrm{T}}
\end{gathered}
$$

Onde: $\mathrm{V}$ é o volume de água (em litros), $\mathrm{M}$ é a quantidade de urânio (em microgramas), S é o inverso da concentração de urânio e A é a razão de atividade ${ }^{234} \mathrm{U} / 238 \mathrm{U}$.

O rearranjo dessas expressões possibilita calcular os volumes relativos das duas águas na mistura, ou seja:

$$
\mathrm{V}_{1} / \mathrm{V}_{\mathrm{T}}=\mathrm{S}_{1} / \mathrm{S}_{\mathrm{T}}\left(\mathrm{A}_{2}-\mathrm{A}_{\mathrm{T}} / \mathrm{A}_{2}-\mathrm{A}_{1}\right)
$$

A água resultante $\mathrm{T}$ possui valores de razão de atividade ${ }^{234} \mathrm{U} /{ }^{238} \mathrm{U}$ e inverso de concentração de urânio pertencentes à reta que une os dados relativos às águas 1 e 2 , conforme ilustra a figura 3. Quando se tem três águas de diferentes procedências, caracterizadas por distintos valores de concentração de $U$ e razão de atividade ${ }^{234} U /{ }^{238} U$, da sua mistura poderá resultar uma água cujos valores de $\mathrm{A}$ e $\mathrm{S}$ inserem-se dentro de um triângulo formado pelos dados relativos aos três componentes (Figura 3). Se um sistema desse tipo é reconhecido, então, existe uma solução única para os volumes relativos das águas na mistura, por exemplo, as proporções volumétricas entre a água $1 \mathrm{e}$ a resultante da mistura e entre a água 2 e a resultante da mistura são equacionadas pelas expressões:

$$
\begin{gathered}
\frac{\mathrm{V}_{1}}{\mathrm{~V}_{\mathrm{T}}}=\frac{\mathrm{S}_{1}}{\mathrm{~S}_{\mathrm{T}}} \cdot \frac{\left[\left(\mathrm{S}_{T}-\mathrm{S}_{3}\right)\left(\frac{\mathrm{A}_{3}-\mathrm{A}_{2}}{\mathrm{~S}_{3}-\mathrm{S}_{2}}\right)-\left(\mathrm{A}_{\mathrm{T}}-\mathrm{A}_{3}\right)\right]}{\left[\left(\mathrm{S}_{1}-\mathrm{S}_{3}\right) \cdot\left(\frac{\mathrm{A}_{3}-\mathrm{A}_{2}}{\mathrm{~S}_{3}-\mathrm{S}_{2}}\right)-\left(\mathrm{A}_{1}-\mathrm{A}_{3}\right)\right]} \\
\frac{\mathrm{V}_{2}}{\mathrm{~V}_{\mathrm{T}}}=\frac{\mathrm{S}_{2}}{\mathrm{~S}_{\mathrm{T}}} \cdot \frac{\left[\left(\mathrm{S}_{\mathrm{T}}-\mathrm{S}_{1}\right)\left(\frac{\mathrm{A}_{1}-\mathrm{A}_{3}}{\mathrm{~S}_{1}-\mathrm{S}_{3}}\right)-\left(\mathrm{A}_{\mathrm{T}}-\mathrm{A}_{1}\right)\right]}{\left[\left(\mathrm{S}_{2}-\mathrm{S}_{1}\right)\left(\frac{\mathrm{A}_{1}-\mathrm{A}_{3}}{\mathrm{~S}_{1}-\mathrm{S}_{3}}\right)-\left(\mathrm{A}_{2}-\mathrm{A}_{1}\right)\right]}
\end{gathered}
$$

OSMOND et al. (1974) comentaram que quando o comportamento do urânio ou da RA não é conservativo, torna-se difícil distinguir as relações de mistura e tendências evolucionárias das águas no aquífero. Essas tendências incluiriam processos como o aumento do ${ }^{234} \mathrm{U}$ devido ao recuo alfa do ${ }^{234} \mathrm{Th}$, a diminuição de ${ }^{234} \mathrm{U}$ por decaimento de seu excesso, a diluição por água fresca introduzida no sistema, a precipitação do urânio, a concentração de sais por evapotranspiração e a lixiviação do urânio com diferentes composições isotópicas (Figura 4). Se RA é diferente de 1, o excesso ou deficiência de ${ }^{234} \mathrm{U}$ variaria de acordo com sua meia-vi- 
da de cerca de 250.000 anos e as águas confinadas acumulariam ${ }^{234} \mathrm{U}$ por processos de recuo alfa. Os processos de diluição ou precipitação não provocariam mudanças na RA e a lixiviação de urânio da rocha circundante causaria mudanças tanto em sua concentração quanto na RA.

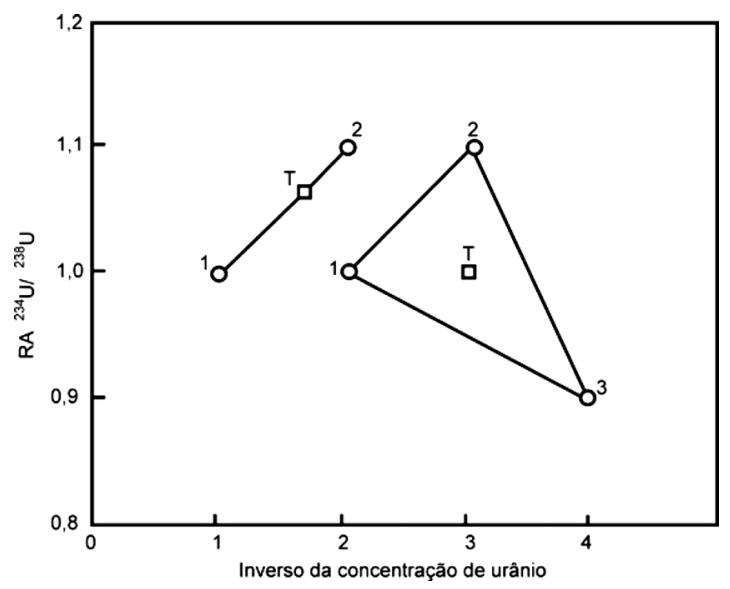

FIGURA 3 - Modelo para dedução de proporções de mistura. 1,2,3 = águas que se misturam; $\mathrm{M}=$ água resultante; $\mathrm{T}=$ água resultante para mistura de iguais volumes. Adaptado de OSMOND et al. (1974).

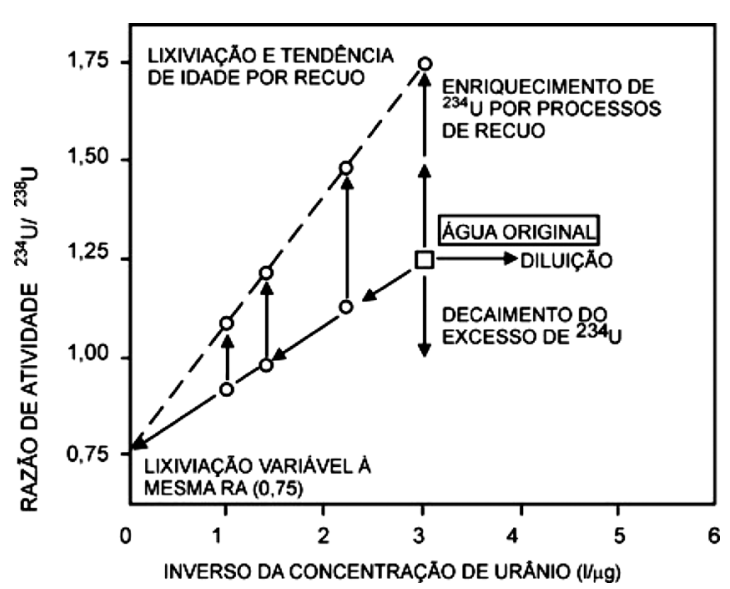

FIGURA 4 - Modelo ilustrando possíveis tendências evolucionárias das variações isotópicas do urânio dissolvido em águas subterrâneas. Adaptado de OSMOND \& COWART (1976).

\subsection{Circulação de águas e o desequilíbrio radioativo}

OSMOND \& COWART (1976) apresentaram dois modelos baseados no desequilíbrio radioativo dos isótopos de urânio dissolvidos em águas subterrâneas presentes em regiões de estratos permeáveis e impermeáveis. O primeiro modelo seria aplicado a estratos impermeáveis ou terrenos elevados, os quais contribuem para que o regime de circulação das águas seja mais superficial, as quais são mais oxidantes. Neste caso, os processos de lixiviação e de recuo alfa resultariam em concentração média a baixa para o urânio dissolvido e elevada para a RA; por outro lado, os solos e sedimentos erodidos exibiriam valores de RA menores que a unidade, isto é, $R A<1$. Esta situação está ilustrada na figura $5 \mathrm{a}$.

O segundo modelo seria aplicável a regiões caracterizadas por rochas permeáveis ou zonas de recarga de aquíferos. Neste caso, a infiltração se torna importante, sendo o urânio lixiviado pela água que percola o terreno. O urânio lixiviado das zonas mais superficiais (oxidadas) tenderia a se acumular nas zonas mais profundas (redutoras). Ao penetrar maiores profundidades, a água apresentaria concentração baixa de urânio dissolvida e alta RA, devido ao recuo alfa do ${ }^{234} \mathrm{U}$ gerado pelas camadas de urânio nestas zonas. As zonas de acumulação de urânio teriam baixos valores de RA e as águas de circulação mais superficial seriam portadoras de altas concentrações de urânio dissolvido e baixas RA. Este modelo está ilustrado na figura $5 \mathrm{~b}$.
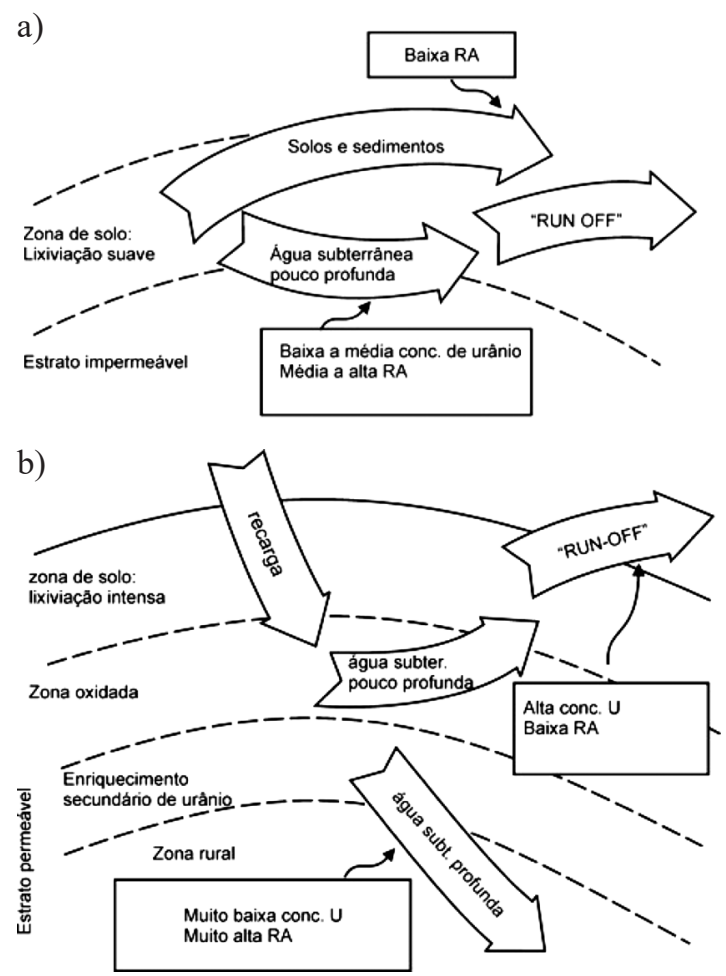

FIGURA 5 - Modelo isotópico de urânio aplicável a (a) terrenos impermeáveis e (b) terrenos permeáveis. Adaptado de OSMOND \& COWART (1976). 
OSMOND \& COWART (1976) caracterizaram os sistemas de águas subterrâneas em termos de b e RA (se C é a concentração de ${ }^{238} \mathrm{U}$, b é o "excesso de ${ }^{234} \mathrm{U}$ " em equivalentes de ${ }^{238} \mathrm{U}$, isto é, $\mathrm{b}=$ $\mathrm{RA} \times \mathrm{C}$ ). Na figura 6 estão ilustrados b e RA para vários aquíferos, onde é possível notar que: o setor superior esquerdo corresponde a lixiviação com baixos valores de RA (caracteriza aquíferos com barreiras redutoras); o setor inferior direito reflete lixiviação ou recuo $\alpha$ com altos valores de RA (caracteriza aquíferos oxidantes); o setor inferior esquerdo corresponde a baixos excessos de ${ }^{234} \mathrm{U}$ (caracteriza águas reduzidas como aquelas encontradas em sistemas geotermais); o setor superior direito reflete altos excessos de ${ }^{234} \mathrm{U}$ (caracteriza aquíferos portadores de mineralização de urânio).

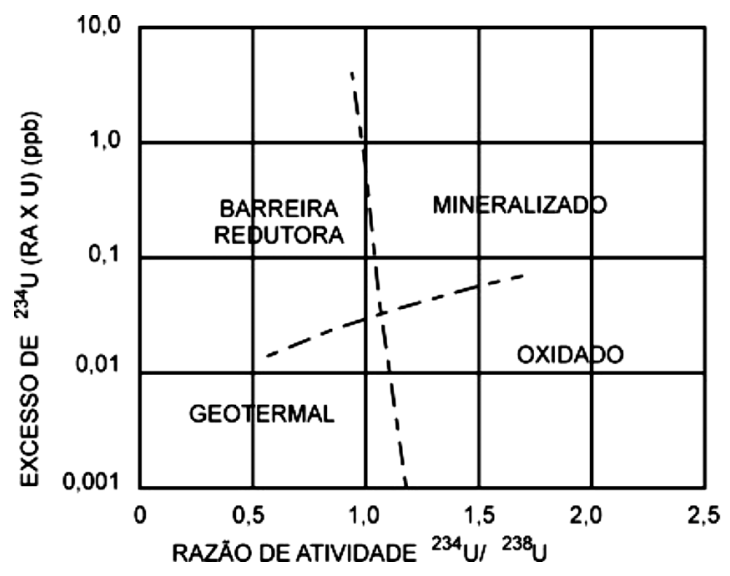

FIGURA 6 - Caracterização de sistemas de águas subterrâneas em termos de "excesso de ${ }^{234} \mathrm{U}$ " e RA. Adaptado de OSMOND \& COWART (1976).

\subsection{Datação de águas subterrâneas}

Os inúmeros experimentos de lixiviação descritos por BONOTTO \& ANDREWS $(1993,2000)$ e BONOTTO et al. (2001) mostraram que o ${ }^{234} \mathrm{U}$ é dissolvido preferencialmente em relação ao ${ }^{238} \mathrm{U}$ em rochas e solos, confirmando os resultados de outras investigações, de maneira que a taxa de dissolução do ${ }^{234} \mathrm{U}$ é diferente daquela do ${ }^{238} \mathrm{U}$. KIGOSHI (1971) também sugeriu que o recuo alfa do ${ }^{234} \mathrm{Th}$ da superfície da rocha para a fase líquida constitui outro importante mecanismo que enriquece as águas em ${ }^{234}$ U. ANDREWS \& KAY (1978) propuseram a seguinte equação para prever a geração de uma razão de atividade ${ }^{234} \mathrm{U} / 238 \mathrm{U}$ (RA) para o urânio dis- solvido, através da combinação dos processos de lixiviação e recuo, ocorrendo desde " $t$ " anos atrás:

$$
\mathrm{RA}=\frac{0,235 \mathrm{R}\left(1-e^{-\lambda t}\right)}{K_{8} t}+\frac{K_{4}}{K_{8}}
$$

onde $R$ corresponde à distância de recuo do ${ }^{234} \mathrm{Th}$ na rocha matriz (cerca de $3 \times 10^{-6} \mathrm{~cm}$ ), 0,235 é a fração de átomos de ${ }^{234}$ Th nessa distância que pode deixar a superfície do mineral por recuo alfa e atingir a solução, $\lambda$ é a constante de decaimento do ${ }^{234} \mathrm{U}$ e $K_{4}$ e $K_{8}$ são as constantes de taxa de lixiviação $\left(\mathrm{cm} \cdot \mathrm{a}^{-1}\right)$ para a dissolução $\mathrm{de}^{234} \mathrm{U}$ e ${ }^{238} \mathrm{U}$, respectivamente.

A dissolução mais ativa de urânio ocorre em condições oxidantes, as quais geralmente se verificam na zona de recarga do aquífero. Uma água subterrânea que dissolveu urânio próximo à recarga pode sofrer mudança no teor desse elemento devido a uma lixiviação adicional, ou, se o potencial de óxi-redução muda para condições redutoras, devido deposição de urânio e posterior enriquecimento em ${ }^{234} \mathrm{U}$ por processos de recuo alfa do ${ }^{234} \mathrm{Th}$. ANDREWS et al. (1982) estabeleceram um modelo de evolução da razão de atividade ${ }^{234} \mathrm{U} / 238 \mathrm{U}$, depois que a água subterrânea penetra a zona redutora caracterizada pela dominância dos processos de recuo alfa do ${ }^{234} \mathrm{Th}$, definido a partir da equação:

$$
\mathrm{RA}_{\mathrm{t}}=1+\left(\mathrm{RA}_{\mathrm{i}}-1\right) \mathrm{e}^{-\lambda t}+0,235 \rho \mathrm{SR}\left(1-\mathrm{e}^{-\lambda t}\right)[\mathrm{U}]_{\mathrm{r}} /[\mathrm{U}]_{\mathrm{s}}
$$

onde, $R A_{i}$ e $R A_{t}$ são as razões de atividade ${ }^{234} \mathrm{U} / 238 \mathrm{U}$ da água subterrânea, respectivamente, antes e após penetrar a zona redutora; $t$ é o tempo em anos transcorrido até a água atingir a zona redutora

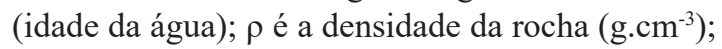
$[U]_{r}$ e $[U]_{s}$ são os teores de urânio na rocha e água subterrânea em $\mu \mathrm{g} / \mathrm{g} \mathrm{e} \mu \mathrm{g} / \mathrm{cm}^{3}$, respectivamente; $S$ é a área superficial de rocha em contato com determinado volume de água subterrânea $\left(\mathrm{cm}^{2} / \mathrm{cm}^{3}\right)$ e os demais parâmetros são os mesmos referidos anteriormente. O segundo termo nesta equação representa o decaimento do excesso de ${ }^{234} \mathrm{U}$ adquirido por lixiviação seletiva antes que a água subterrânea atingisse as condições redutoras, ao passo que o terceiro termo avalia o enriquecimento da razão de atividade ${ }^{234} U /{ }^{238} U$ na água subterrânea devido ao recuo alfa, depois que atingiu a zona redutora. $O$ valor de $S$ relaciona-se com a área superficial específica s $\left(\mathrm{cm}^{2} / \mathrm{g}\right)$ e porosidade total $\varnothing$ do aquífero pela equação $S=\rho s / \varnothing$, sendo sua magnitude dependente da natureza da porosidade do aquífero, de maneira que os valores nos aquíferos cujo fluxo é intergranular são maiores que aqueles nos quais o 
fluxo se dá predominantemente através das grandes fraturas.

A equação (20) assume taxas uniformes de dissolução de urânio, acompanhadas por processos de recuo, incluindo a adição de termos de sistemas abertos. Em alguns casos, isto constitui uma violação da premissa de condições uniformes durante um longo período (ANDREWS et al. 1982). Dessa forma, FRÖHLICH \& GELLERMANN (1987) propuseram um modelo fenomenológico para a evolução da composição isotópica do urânio ao longo de trajetórias de fluxo baseadas numa equação de transporte (dispersão), assumindo que os processos de sorção que afetam o ${ }^{238} \mathrm{U},{ }^{234} \mathrm{Th}$ e ${ }^{234} \mathrm{U}$ são de cinética de primeira ordem. $\mathrm{O}$ modelo de Fröhlich-Gellermann foi modificado por IVANOVICH et al. (1991), onde, adicionalmente à dissolução (lixiviação), a taxa de ejeção por recuo do nuclídeo filho foi assumida ser proporcional à concentração do nuclídeo pai na rocha matriz. Por outro lado, sob condições de estado estacionário esperadas após as frentes de óxi-redução características das barreiras geoquímicas, o modelo simples do decaimento radioativo do excesso de ${ }^{234} \mathrm{U}$ em solução foi demonstrado por IVANOVICH et al. (1991) como sendo um caso especial do modelo mais generalizado. O modelo simplificado é útil para a datação de águas subterrâneas no intervalo de $\sim 10 \mathrm{ka}-1.5$ Ma naquelas porções do aquífero onde virtualmente não ocorre atividade geoquímica envolvendo o urânio nas fases líquida e sólida. Isto pode ser representado pela seguinte equação (IVANOVICH et al. 1991):

$$
(\mathrm{AR}-1)_{\mathrm{t}}=(\mathrm{AR}-1)_{\mathrm{i}} \mathrm{e}^{-\lambda t}
$$

onde: $A R=$ razão de atividade ${ }^{234} \mathrm{U} / 238 \mathrm{U} ; t=$ tempo requerido para a migração de $\mathrm{U}$ ao longo de trajetória de fluxo subterrâneo do maior (subscrito i) para o menor (subscrito $t$ ) nível piezométrico no aquífero; $\lambda=$ constante de decaimento do ${ }^{234} \mathrm{U}$.

\section{ESTUDOS REALIZADOS NO BRASIL}

Um modelo utilizando os isótopos de urânio ${ }^{238} \mathrm{U}$ e ${ }^{234} \mathrm{U}$ para o estudo de processos intempéricos foi desenvolvido por MOREIRA-NORDEMANN (1977) e aplicado a duas bacias hidrográficas na região semiárida no estado da Bahia: Rio Preto e Rio Salgado. O trabalho pioneiro realizado no Brasil para uso hidrogeológico dos isótopos de urânio ${ }^{238} \mathrm{U}$ e ${ }^{234} \mathrm{U}$ foi o de GOMES (1978) no estudo do aquífero calcário Bambuí (BA). Houve uma tentativa de datação das águas subterrâneas baseada na utilização de premissas diferentes daquelas inerentes às equações (20) e (21). O desequilíbrio isotópico do urânio demonstrou estar relacionado com a estrutura hidrogeológica regional. $\mathrm{Na}$ área de recarga, as razões de atividade ${ }^{234} U / 238 U$ variaram entre 3 e 6 e, fora dela, as razões aumentaram na direção norte, chegando a atingir valores próximos a 10 . O excesso de ${ }^{234} \mathrm{U}$ relativamente à razão de atividade básica (razão de lixiviação fundamental) exibiu um comportamento congruente com os dados hidrogeológicos, fornecendo informações úteis acerca da área de recarga e direção de fluxo subterrâneo.

CHAPMAN et al. (1993) descreveram vários estudos envolvendo a mina de urânio Osamu Utsumi e o depósito de tório/terras raras no Morro do Ferro, Planalto de Poços de Caldas (MG), com o propósito de gerar informações para o armazenamento seguro de rejeitos radioativos, inserindo-se nesse contexto as razões de atividade ${ }^{234} \mathrm{U} /{ }^{238} \mathrm{U}$ e o seu comportamento em virtude dos processos redox.

Nas águas subterrâneas da estância hidromineral de Águas da Prata (SP), BONOTTO (1993) encontrou correlações significativas entre a razão de atividade ${ }^{234} \mathrm{U} /{ }^{238} \mathrm{U}$ e os seguintes parâmetros hidrogeoquímicos: sólidos totais dissolvidos, intensidade iônica, pressão parcial de $\mathrm{CO}_{2}$ e índice de troca de bases. Os resultados indicaram que o enriquecimento de ${ }^{234} \mathrm{U}$ em solução aumenta de acordo com o grau de intemperismo nos aquíferos e que uma maior razão de atividade ${ }^{234} \mathrm{U} / 238 \mathrm{U}$ está relacionada com um maior valor da taxa de dissolução. $\mathrm{Na}$ mesma área de estudo, foi também identificada uma correlação inversa entre a razão de ativida$\mathrm{de}^{234} \mathrm{U} /{ }^{238} \mathrm{U}$ e a concentração de atividade do ${ }^{222} \mathrm{Rn}$ dissolvido, a qual indicou diferentes mecanismos de dissolução dos radionuclídeos ${ }^{234} \mathrm{Ue} \mathrm{e}^{222} \mathrm{Rn}$ na interface água-rocha.

BONOTTO (1994) descreveu os resultados de análises isotópicas de urânio em águas subterrâneas provenientes de diversos furos de sondagem perfurados no depósito de tório e terras raras situado no Morro do Ferro, próximo ao centro do Planalto de Poços de Caldas, estado de Minas Gerais. Coletaram-se as amostras em períodos de seca e de chuvas, sendo que as mesmas procederam de aquíferos desenvolvidos no manto de intemperismo, caracterizado por intensa alteração in situ, com a zona alterada constituindo um laterito argiloso de espessura maior que $100 \mathrm{~m}$. Empregaram-se a razão isotópica ${ }^{234} \mathrm{U} /{ }^{238} \mathrm{U}$ e o teor de urânio dissolvido mensurados por espectrometria alfa para cada amostra, para fins de avaliação 
da aplicabilidade, na área, do modelo desenvolvido para a dedução de proporções de águas subterrâneas numa mistura. A influência pluviométrica na utilização do modelo isotópico de urânio foi considerada, assim como foi possível indicar os furos de sondagem que estariam fornecendo amostras representativas de distintos sistemas de circulação de águas subterrâneas.

Segundo SILVEIRA \& BONOTTO (1995), o teor de urânio dissolvido nas águas subterrâneas da estância hidromineral de Águas de Lindóia (SP) variou de 0,001 a $0,509 \mu \mathrm{g} / \mathrm{L}$, enquanto a razão de atividade ${ }^{234} \mathrm{U} / 238 \mathrm{U}$ para as fontes estudadas situou-se entre 0,81 e 3,76, correspondendo ao intervalo de variação de 1 a 2 obtido pela maioria dos pesquisadores, dentro das incertezas analíticas dos resultados. Esses resultados mostraram que os isótopos de urânio ${ }^{234} \mathrm{U}$ e ${ }^{238} \mathrm{U}$ estão sendo mobilizados nos aquíferos em virtude dos processos de interação água-rocha. Os dados isotópicos de urânio para as águas analisadas permitiram avaliar modelo disponível em literatura para a prospecção geoquímica de depósitos de urânio na área de Águas de Lindóia, o qual mostrou-se satisfatório para a interpretação dos resultados obtidos, não evidenciando a presença de acumulação de urânio nos estratos lixiviados pelas águas.

BONOTTO (1998) demonstrou a aplicabilidade do modelo isotópico do urânio dissolvido na avaliação de processos de mistura no Sistema Aquífero Guarani (SAG) no município de Ribeirão Preto (SP), onde se coletaram amostras associadas com variações no potencial redox, possivelmente decorrentes do processo de nitrificação. Os resultados obtidos permitiram ajustar uma reta aos dados experimentais, a qual possibilitou considerar a água de um poço tubular como mistura de águas provenientes de outros dois poços. A proporção em volume da água de um poço na mistura é $23 \%$, enquanto a da água do outro poço é de $77 \%$, sugerindo que a água não afetada significativamente pela nitrificação ainda é predominante no sistema de captação envolvendo os três poços.

MANCINI (2002) apresentou resultados da concentração de ${ }^{238} \mathrm{U}$ dissolvido e razão de atividade (RA) ${ }^{234} U / 238 \mathrm{U}$ em amostras de águas subterrâneas coletadas na área do Barreiro, município de Araxá (MG) (Tabela 2). Os pontos foram selecionados em função da direção das linhas de fluxo no aquífero, sendo separados em Perfil 1, Perfil 2 e Perfil 3. A figura 7 mostra a variação da concentração de ${ }^{238} \mathrm{U}$ e razão de atividade (RA) ${ }^{234} \mathrm{U} /{ }^{238} \mathrm{U}$ para os pontos selecionados. A concentração de
${ }^{238} \mathrm{U}$ variou de 0,28 a $5,46 \mu \mathrm{g} / \mathrm{L}$, estando a maioria dos pontos abaixo de $1 \mu \mathrm{g} / \mathrm{L}$ (a única exceção é o ponto 9sb) (Tabela 2). A RA variou de 0,91 a 2,69, o maior valor sendo obtido no ponto $17 \mathrm{sb}$ (Tabela 2). A RA apresentou uma tendência para a unidade na direção das linhas de fluxo subterrâneo. $\mathrm{O}$ maior desequilíbrio encontrado foi na parte mais a sul do aquífero, onde a área é mais preservada. Isto denotou ser uma característica da região, pois, o ponto $17 \mathrm{sb}$ também apresentou uma RA maior que os demais pontos, mesmo sendo um dreno na mina de fosfato.

$\mathrm{Na}$ área do Barreiro, o Perfil 1 é constituído pelos pontos $15 \mathrm{sb}, 14 \mathrm{sb}, 9 \mathrm{sb}$ e $3 \mathrm{sb}$ (Tabela 2), estando situado a oeste da mina de fosfato, na direção sudeste-nordeste. A figura 8a mostra o comportamento da RA para esse perfil. A concentração de $\mathrm{U}$ tem um aumento significativo no ponto $9 \mathrm{sb}$, podendo o urânio estar sendo fornecido pelo aterro, onde está o ponto $14 \mathrm{sb}$, que não apresenta um

TABELA 2 - Concentração de ${ }^{238} \mathrm{U}$ dissolvido e razão de atividade (RA) ${ }^{234} \mathrm{U} /{ }^{238} \mathrm{U}$ para amostras de águas subterrâneas do Barreiro, município de Araxá (MG).

\begin{tabular}{cccc}
\hline Amostra & Volume $(L)$ & ${ }^{238} U(\mu g / L)$ & $R A^{234} U /{ }^{238} U$ \\
\hline 3sb & 10,4 & $0,58 \pm 0,16$ & $1,00 \pm 0.24$ \\
$4 \mathrm{sb}$ & 9,7 & $0,59 \pm 0,18$ & $0,94 \pm 0.20$ \\
$5 \mathrm{sb}$ & 10,4 & $0,56 \pm 0,43$ & $1,16 \pm 0.70$ \\
6sb & 10,7 & $0,37 \pm 0,08$ & $1,19 \pm 0.34$ \\
$8 \mathrm{sb}$ & 9,7 & $0,63 \pm 0,38$ & $1,39 \pm 0.74$ \\
$9 \mathrm{sb}$ & 10,7 & $5,46 \pm 1,99$ & $1,02 \pm 0.15$ \\
$10 \mathrm{sb}$ & 10 & $0,28 \pm 0,08$ & $1,18 \pm 0.36$ \\
$11 \mathrm{sb}$ & 10,5 & $0,64 \pm 0,14$ & $0,91 \pm 0.26$ \\
$12 \mathrm{sb}$ & 10,9 & $0,59 \pm 0,18$ & $1,31 \pm 0,30$ \\
$14 \mathrm{sb}$ & 10,5 & $0,99 \pm 0,18$ & $1,42 \pm 0,19$ \\
$15 \mathrm{sb}$ & 10,2 & $0,48 \pm 0,13$ & $1,96 \pm 0,45$ \\
$17 \mathrm{sb}$ & 10,5 & $0,80 \pm 0,27$ & $2,69 \pm 0,58$ \\
\hline
\end{tabular}

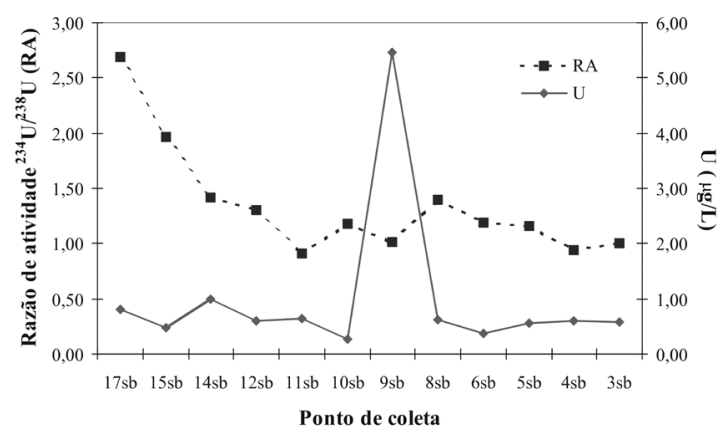

FIGURA 7 - Concentração de urânio e razão de atividade (RA) nas águas subterrâneas do Barreiro, município de Araxá (MG). 
valor elevado para a concentração de ${ }^{238} \mathrm{U}$. No entanto, o ponto $3 \mathrm{sb}$ apresenta um valor para a concentração de ${ }^{238} \mathrm{U}$ bem inferior ao determinado para o ponto $9 \mathrm{sb}$. O ponto $3 \mathrm{sb}$ também é influenciado pela Barragem "E", que pode interferir diretamente no comportamento de suas águas. Variações no potencial redox entre os pontos 9sb e 3sb não puderam explicar o comportamento do urânio dissolvido nas águas do Perfil 1. O Perfil 2 é formado pelos pontos $12 \mathrm{sb}, 8 \mathrm{sb}$ e $6 \mathrm{sb}$ (Tabela 2), situando-se na parte mais central do Barreiro, na direção norte-sul. Representa basicamente a área de recarga formada pelo anel verde da região. A figura $8 b$ mostra a variação da concentração de ${ }^{238} \mathrm{U}$ e da RA para o Perfil 2. Neste perfil, a concentração de urânio diminuiu na direção do fluxo d'água, podendo ocorrer a sua precipitação entre os pontos $8 \mathrm{sb}$ e 6 sb. A RA se manteve praticamente inalterada para os pontos $12 \mathrm{sb}$ e $8 \mathrm{sb}$ com uma ligeira queda para o ponto 6sb, que também está sob influência do Perfil 3. Esse perfil é formado pelos pontos $11 \mathrm{sb}, 10 \mathrm{sb}, 5 \mathrm{sb}, 4 \mathrm{sb}$ e $6 \mathrm{sb}$ (Tabela 2), localizando-se na parte leste do Barreiro, na direção sudeste-nordeste. A Figura 8c mostra o comportamento da concentração de ${ }^{238} \mathrm{U}$ e da RA para este perfil. Os pontos 11 sb e 10 sb estão próximos entre si, ficando quase paralelos na direção leste-oeste. Ambos contribuem com suas águas para o abastecimento dos pontos $6 \mathrm{sb}, 5 \mathrm{sb}$ e $4 \mathrm{sb}$. O ponto $10 \mathrm{sb}$ está bem próximo à barragem "BCM", sendo bem provável que esteja sofrendo influência da mesma, pois, os valores nele encontrados são praticamente similares aos determinados para o ponto $9 \mathrm{sp}$, de $0,13 \mu \mathrm{g} / \mathrm{L}$ para a concentração e 1,22 para a RA (MANCINI \& BONOTTO 2015), que contribui para a formação do lago na área do Barreiro. Os pontos $5 \mathrm{sb} e$ $4 \mathrm{sb}$ apresentam uma pequena diferença tanto para a concentração de ${ }^{238} \mathrm{U}$ quanto para a $\mathrm{RA}$, a qual não caracteriza nenhuma alteração no comportamento das águas em relação à profundidade, pois estes dois poços fazem parte de um conjunto de 4 poços com profundidades diferentes, sendo o $4 \mathrm{sb}$ o mais profundo. No geral, não se tem um padrão de comportamento definido para o Perfil 3, em relação à concentração de ${ }^{238} \mathrm{U}$. A RA se manteve próxima a unidade com pequenas variações. O ponto $6 \mathrm{sb}$ denota estar recebendo contribuição principalmente dos perfis 2 e 3, embora possa também sofrer influência de águas provenientes da porção mais a leste da área.

BONOTTO (2005) demonstrou a possibilidade de emprego do modelo isotópico do urânio dissolvido na avaliação de processos de mistura de águas termais e atermais na estância hidromineral de Poços de Caldas (MG). Como a concentração de urânio é praticamente a mesma para as amostras atermais 1A e 3A (Figura 9), estimou-se uma razão isotópica ${ }^{234} \mathrm{U} / 238 \mathrm{U}$ de 1,4 para representá-las e um valor de 2,5 para representar a razão isotópica ${ }^{234} \mathrm{U} /{ }^{238} \mathrm{U}$ média das amostras de águas termais 1T e 2T (Figura 9). Por estes dois valores médios e, também, pelos dados correspondentes à amostra de água termal $3 \mathrm{~T}$, traçou-se o triângulo ilustrado na figura 9 , onde se nota que a amostra de água atermal 2A (fonte Sinhazinha) insere-se no interior do triângulo. Assim, é possível calcular em que proporções as outras águas estariam contribuindo na mistura que forma a água da fon-
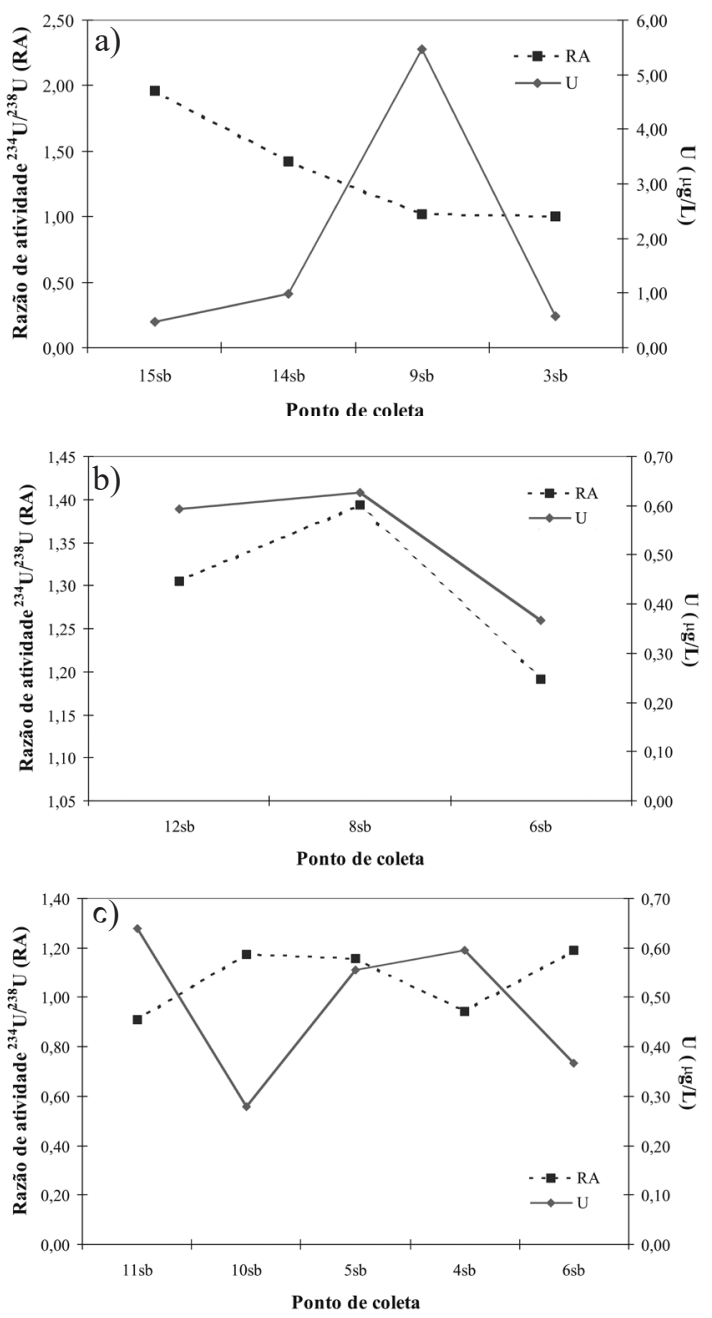

FIGURA 8 - Concentração de urânio e razão de atividade (RA) para as amostras de águas subterrâneas do Barreiro, município de Araxá (MG) no (a) Perfil 1, (b) Perfil 2 e (c) Perfil 3. 
te Sinhazinha. De acordo com o modelo, a fonte Sinhazinha estaria recebendo as seguintes contribuições: $23 \%$ das águas das fontes frias, de circulação mais superficial; $68 \%$ das águas hipertermais, de circulação profunda, e 9\% da água hipotermal (Quisisana Sulfurosa), provavelmente circulando a profundidades intermediárias. Portanto, a modelagem é promissora para interpretar as principais características observadas nas águas subterrâneas de Poços de Caldas (MG).

A equação (20) foi aplicada com sucesso por ANDREWS et al. (1982) e ANDREWS \& KAY (1982, 1983) na datação de águas subterrâneas de aquíferos em terrenos sedimentares e cristalinos. As condições hidrogeoquímicas envolvendo o potencial redox, teor de urânio dissolvido e razão isotópica ${ }^{234} \mathrm{U} / 238 \mathrm{U}$ numa secção do SAG no estado de São Paulo favoreceram a sua utilização por BONOTTO (2006) em pontos de coleta de amostras de águas subterrâneas. Para isto, foram considerados os seguintes parâmetros:

(1) porosidade da rocha igual a $15 \%$, representando a média dos valores referidos por REBOUÇAS (1976);

(2) diâmetro médio dos grãos no arenito igual a 0,1875 mm, referido por GILBOA et al. (1976), o qual possibilita estimar a área superficial especí-

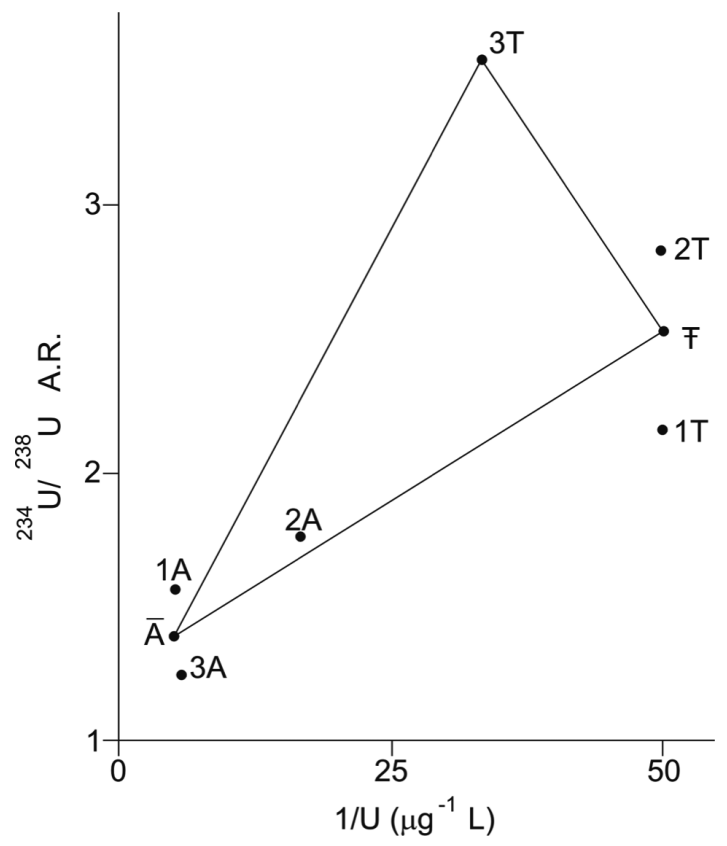

FIGURA 9 - Razão de atividade ${ }^{234} \mathrm{U} /{ }^{238} \mathrm{U}$ em função do inverso da concentração de urânio para amostras de águas subterrâneas de Poços de Caldas (MG). fica da rocha pela equação $\mathrm{s}=3 / \rho \mathrm{\rho}$, onde $r$ é o raio do grão e $\rho$ é a densidade da rocha;

(3) densidade média dos arenitos pouco consolidados $\rho=1,65 \mathrm{~g} / \mathrm{cm}^{3}$;

(4) $S$ igual a $2133 \mathrm{~cm}^{-1}$, estimado a partir dos parâmetros (1), (2) e (3);

(5) $\lambda$ do ${ }^{234} \mathrm{U}$ igual a $2,79 \times 10^{-6} \mathrm{ano}^{-1}$;

(6) $[U]_{r}$ igual a $0,70 \mu \mathrm{g} / \mathrm{g}$, representando a média dos valores obtidos por KIMMELMANN et al. (1995);

(7) $[U]_{s}$ igual a $0,01 \mu \mathrm{g} / \mathrm{L}$, representando a concentração do urânio dissolvido nas zonas mais redutoras que ocorrem nas porções mais profundas do aquífero;

(8) $R A_{i}$ igual a 1,3, consistindo na RA inicial do U dissolvido em água subterrânea diluída que ocorre em zona oxidante do aquífero;

(9) $R A_{t}$ igual a 21,65 , representando RA nas zonas mais redutoras que ocorrem nas porções mais profundas do aquífero.

Quando todos esses valores são substituídos na equação (20), verifica-se que uma idade de 45 ka é obtida. Porém, adotando-se outros valores para a porosidade, $[U]_{r}, R A_{t}$ e $[U]_{s}$ na equação (20) é possível calcular outros valores para a idade, por exemplo, $61 \mathrm{ka}$ ou mesmo $635 \mathrm{ka}$. Esse último valor é praticamente coincidente com a estimativa de 640 ka obtida a partir do emprego da equação (21) numa sub-bacia selecionada do SAG na qual se considerou uma transecta SE-NW no estado de São Paulo (BONOTTO 2006).

REYES (2009) determinou as razões isotópicas ${ }^{234} \mathrm{U} /{ }^{238} \mathrm{U}$ e ${ }^{87} \mathrm{Sr} /{ }^{86} \mathrm{Sr}$ em amostras de águas subterrâneas coletadas em cinco poços profundos que interceptaram as rochas graníticas da Suíte Intrusiva de Itu, localizada na borda leste do estado de São Paulo, nos municípios de Salto, Itu, Itupeva e Indaiatuba. A composição isotópica do $\mathrm{Sr}$ nas águas mostrou ser dependente não só da idade e da razão $\mathrm{Rb} / \mathrm{Sr}$ das rochas percoladas, mas também da solubilidade dos diferentes minerais lixiviados. As variações encontradas nas concentrações de atividade do ${ }^{238} \mathrm{U}^{2}{ }^{234} \mathrm{U}$ nas águas sugeriram relação com vários fatores como o grau de confinamento do aquífero e, principalmente, a composição química e parâmetros físico-químicos dessas águas. Nos diagramas da razão de atividade ${ }^{234} \mathrm{U} /{ }^{238} \mathrm{U} v s$. inverso da concentração de $\mathrm{U}$, observou-se que a dinâmica de circulação das águas foi bem mais complexa do que aquela envolvendo apenas misturas de dois componentes distintos, pois, os resultados obtidos não se ajustaram a uma reta. As razões ${ }^{234} \mathrm{U} /{ }^{238} \mathrm{U}$ denotaram que os processos de recarga 
dos aquíferos ocorrem de maneira distinta, devido aos diferentes sistemas de fraturas, sendo também afetados pelas heterogeneidades químicas das rochas percoladas.

Buscando interpretar os desequilíbrios radioativos entre ${ }^{234} U$ e ${ }^{238} U$ nas águas subterrâneas que ocorrem em granitóides do Complexo Itu (SP), SILVA (2011) conduziu, sob condições controladas de laboratório, experimentos de lixiviação de seis amostras representativas das diferentes fácies graníticas do Complexo Itu. As razões de atividade ${ }^{234} U /{ }^{238} U$ determinadas nas soluções indicaram acentuado desequilíbrio radioativo, com valores variando entre 1,63 e 2,9, indicando lixiviação preferencial do ${ }^{234} \mathrm{U}$. Esses enriquecimentos de ${ }^{234} \mathrm{U}$ não foram causados por recuo alfa direto, devendo-se à fragilização da rede cristalina dos minerais contendo urânio e à mudança no estado de oxidação deste elemento de 4+ para 6+. Tais resultados corroboraram aqueles obtidos em estudos prévios conduzidos por BONOTTO \& ANDREWS (1993, 2000) e BONOTTO et al. (2001), quando haviam sido utilizadas outras rochas matrizes que foram submetidas a diferentes protocolos experimentais de lixiviação.

BONOTTO (2013) utilizou o modelo isotópico do urânio dissolvido para investigar processos de mistura ocorrendo no SAG e aquíferos Bauru e Serra Geral no estado de São Paulo. Os isótopos ${ }^{238} \mathrm{U}$ e ${ }^{234} \mathrm{U}$ forem traçadores úteis na avaliação das proporções relativas de águas de composição variável que se misturam ao longo de diferentes transectas no estado de São Paulo. Os valores médios obtidos para a concentração de urânio dissolvido e razão de atividade ${ }^{234} \mathrm{U} / 238 \mathrm{U}$ possibilitaram traçar uma reta na qual as águas do aquífero Bauru corresponderiam a mistura de águas do SAG $(1,5 \%)$ e aquífero Serra Geral $(98,5 \%)$.

SILVA \& BONOTTO (2015) analisaram 64 amostras de águas subterrâneas no estado do Amazonas, encontrando valores entre 0,01 e 1,4 $\mu \mathrm{g} / \mathrm{L}$ para a concentração de urânio dissolvido e entre 1,0 e 3,5 para a razão de atividade ${ }^{234} U{ }^{238} U$. Foi possível identificar uma tendência de aumento nos valores das RAs no município de Manaus (AM), acompanhando a direção do fluxo subterrâneo. A RA também aumentou na direção SWNE, correspondendo aos seguintes municípios: Uarini $\rightarrow$ Tefé; Manacapuru $\rightarrow$ Manaus; Presidente Figueiredo $\rightarrow$ São Sebastião do Uatumã; e Boa Vista do Ramos $\rightarrow$ Parintins. Estas tendências estão relacionadas a vários fatores, dentre eles, o crescente caráter ácido das águas.
BONOTTO $(2016,2017)$ descreveu um estudo hidrogeoquímico enfocando águas subterrâneas de estâncias hidrominerais nos estados de São Paulo e Minas Gerais. Foram analisadas 75 amostras provenientes de fontes e poços tubulares profundos, para as quais também foi determinada a concentração de urânio dissolvido (variou de 0,001 a $4,82 \mu \mathrm{g} / \mathrm{L}$ ) e razão de atividade ${ }^{234} \mathrm{U} /{ }^{238} \mathrm{U}$ (variou de 1 a 11,7). Foi possível demonstrar a utilidade do modelo isotópico do urânio na avaliação da mistura de águas subterrâneas de distintos sistemas aquíferos, conforme sumarizado na tabela 3 e figura 10 .

\section{CONSIDERAÇÕES FINAIS}

Os isótopos naturais de urânio ${ }^{234} \mathrm{U} \mathrm{e}^{238} \mathrm{U}$ geralmente encontram-se em situações de desequilíbrio radioativo em decorrência dos processos de interação água/solo-rocha. Essa condição tem propiciado o desenvolvimento de equações e modelos visando aplicações geocronológicas, permitindo realizar datações na escala de tempo de até cerca 1,5 Ma, as quais também incluem a determinação de taxas de sedimentação em bacias hidrográficas em função dos processos de intemperismo. A partir da década de 1960, teve início sua aplicação em investigações hidrogeológicas, não só enfocando a avaliação do tempo de residência das águas subterrâneas, mas também dos processos relacionados com a circulação e mistura das águas nos diferentes sistemas aquíferos. A idade de uma massa de água subterrânea é um parâmetro difícil de avaliar, pois, a técnica analítica utilizada pode fornecer um valor que não esteja relacionado com as mudanças geoquímicas que ocorrem durante a sua evolução, sendo necessário, além disso, que a amostra seja representativa da formação da qual foi coletada. Assim, qualquer que seja a metodologia usa$\mathrm{da}$, premissas apropriadas devem ser obedecidas de maneira a se fornecer uma interpretação plausível ao valor obtido. O emprego das variações da razão isotópica ${ }^{234} \mathrm{U} / 238 \mathrm{U}$ do urânio dissolvido para a datação de águas subterrâneas é complicado devido ao fato de que o urânio em solução não forma um sistema quimicamente fechado, pois a dissolução ou deposição de urânio e o crescimento de ${ }^{234} \mathrm{U}$ em virtude do recuo alfa do ${ }^{234} \mathrm{Th}$ na interface água/rocha podem ocorrer na medida em que a água subterrânea migra no aquífero. Outros radionuclídeos utilizados para a datação de águas subterrâneas, como por exemplo o ${ }^{3} \mathrm{H},{ }^{14} \mathrm{C},{ }^{36} \mathrm{Cl}$ e o ${ }^{81} \mathrm{Kr}$, também possuem suas especificidades que devem ser atendidas para que a idade obtida possa ser considerada 
TABELA 3 - Estimativa baseada no modelo isotópico do urânio dissolvido dos volumes relativos da mistura de águas subterrâneas de diferentes sistemas aquíferos nos estados de São Paulo e Minas Gerais.

\begin{tabular}{|c|c|c|c|c|c|}
\hline Cidade & No. & Sigla & Cenário 1 & Cenário 2 & Cenário 3 \\
\hline & 1 & SEI & & & \\
\hline & 2 & JOR & & & \\
\hline Termas de Ibirá (SP) & 1 e 2 (Média) & & $88 \%$ & $89 \%$ & \\
\hline 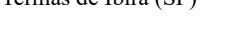 & $\begin{array}{l}3 \\
4\end{array}$ & $\begin{array}{l}\text { CGO } \\
\text { ADB }\end{array}$ & $\begin{array}{l}10 \% \\
2 \%\end{array}$ & $11 \%$ & \\
\hline & 5 (Mista) & SRC & $\begin{array}{l}2 \% \\
100 \%\end{array}$ & $100 \%$ & \\
\hline & 1 & SAT & $36,9 \%$ & & \\
\hline & 2 & LAN & $36,9 \%$ & & \\
\hline & 3 & SLU & $26,2 \%$ & & \\
\hline & 4 (Mista) & SJO & $100 \%$ & & \\
\hline Serra Negra (SP) & 1 & SAT & $37,3 \%$ & $61,8 \%$ & \\
\hline & 5 & BRU & $47,8 \%$ & $13,5 \%$ & \\
\hline & 6 & ITA & $14,9 \%$ & $24,7 \%$ & \\
\hline & 7 (Mista) & SAA & $100 \%$ & & \\
\hline & 8 (Mista) & SCA & & $100 \%$ & \\
\hline & 2 & BEL & $37,4 \%$ & & \\
\hline & 4 & SRE & $62,6 \%$ & & \\
\hline & 7 (Mista) & COM & $100 \%$ & & \\
\hline & 2 & BEL & $46,7 \%$ & & \\
\hline & 3 & LIN & $53,3 \%$ & & \\
\hline & 6 (Mista) & FIL & $100 \%$ & & \\
\hline & & CUR & $51,4 \%$ & & \\
\hline & 2 & BEL & $20,4 \%$ & & \\
\hline & 3 & LIN & $28,2 \%$ & & \\
\hline & 5 (Mista) & SIL & $100 \%$ & & \\
\hline & & BEL & $32,5 \%$ & & \\
\hline Águas de Lindóia (SP) & 4 & SRE & $24,2 \%$ & & \\
\hline & 5 & SIL & $43,3 \%$ & & \\
\hline & 6 (Mista) & FIL & $100 \%$ & & \\
\hline & & BEL & $15,4 \%$ & & \\
\hline & 7 & $\mathrm{COM}$ & $42,8 \%$ & & \\
\hline & 5 & SIL & $41,8 \%$ & & \\
\hline & 6 (Mista) & FIL & $100 \%$ & & \\
\hline & (2) & CUR & $65,3 \%$ & $28,2 \%$ & \\
\hline & 2 & BEL & $14,8 \%$ & $38,9 \%$ & \\
\hline & 4 & SRE & $19,8 \%$ & $32,8 \%$ & \\
\hline & 5 (Mista) & SIL & $100 \%$ & & \\
\hline & 6 (Mista) & FIL & & $100 \%$ & \\
\hline & 3 & VIL & & & \\
\hline & 4 ardia & VIT & & & \\
\hline & 3 e 4 (Média) & PDF & $\begin{array}{l}9,5 \% \\
89 \%\end{array}$ & $\begin{array}{l}1,4 \% \\
967 \%\end{array}$ & $\begin{array}{l}13,7 \% \\
63,4 \%\end{array}$ \\
\hline Aguas da Prata (SP) & $\begin{array}{l}1 \\
2\end{array}$ & $\begin{array}{l}\text { PDE } \\
\text { POL }\end{array}$ & $0,7 \%$ & $1,9 \%$ & $22,9 \%$ \\
\hline & 5 (Mista) & $\mathrm{BOI}$ & $100 \%$ & & \\
\hline & 6 (Mista) & PTA & & $100 \%$ & \\
\hline & 7 (Mista) & PLA & & & $100 \%$ \\
\hline & 1 & PEB and MAC (mean) & $68 \%$ & & \\
\hline Pocos de Caldas (MG) & 2 & FRA and QUI (mean) & $23 \%$ & & \\
\hline & 3 & NOV & $9 \%$ & & \\
\hline & 4 (Mista) & SIN & $100 \%$ & & \\
\hline & 1 & AMO & $78 \%$ & & \\
\hline Pocinhos do & 2 & SMA & $1 \%$ & & \\
\hline Rio Verde (MG) & 3 & SAJ & $21 \%$ & & \\
\hline & 4 (Mista) & RIV & $100 \%$ & & \\
\hline & 9 & SL9 & $15,4 \%$ & & \\
\hline & & SL10 & $84,6 \%$ & & \\
\hline & 5 (Mista) & SL5 & $100 \%$ & & \\
\hline & 9 & SL9 & $55,6 \%$ & & \\
\hline & & SL7 & $44,4 \%$ & & \\
\hline & 6 (Mista) & SL6 & $100 \%$ & & \\
\hline Sร̃oL Lurrenco (MG) & 7 & SL7 & $50 \%$ & & \\
\hline Sao Lourenço (MG) & 10 & SL10 & $50 \%$ & & \\
\hline & 4 (Mista) & SL4 & $100 \%$ & & \\
\hline & 10 & SL10 & $87 \%$ & $43.9 \%$ & \\
\hline & 9 & SL9 & $5,4 \%$ & $41.8 \%$ & \\
\hline & 7 & SL7 & $7,6 \%$ & $14.3 \%$ & \\
\hline & 1 (Mista) & SL1 & $100 \%$ & & \\
\hline & 3 (Mista) & SL3 & & $100 \%$ & \\
\hline & 1 & VIO & $94,8 \%$ & & \\
\hline & 6 & LEO & $5,2 \%$ & & \\
\hline & 8 (Mista) & DXE & $100 \%$ & & \\
\hline & 1 & $\mathrm{VIO}$ & $10,5 \%$ & & \\
\hline & 2 & ISA & $8,3 \%$ & & \\
\hline Caxambu (MG) & 3 & VEN & $81,4 \%$ & & \\
\hline & 4 (Mista) & MAY & $100 \%$ & & \\
\hline & 1 & VIO & $79 \%$ & & \\
\hline & 5 & $\mathrm{BZA}$ & $17,2 \%$ & & \\
\hline & 6 & LEO & $3,8 \%$ & & \\
\hline & 7, 9, 10 (Média) - Mista & EGU, GFL, DPE & $100 \%$ & & \\
\hline & 2 & LA2 & & & \\
\hline & 6 & LA6 & & & \\
\hline & $\underset{4}{2}$ e 6 (Média) & LA4 & $\begin{array}{l}11,7 \% \\
88,3 \%\end{array}$ & & \\
\hline Lambari (MG) & 3 (Mista) & LA3 & $100 \%$ & & \\
\hline & 2 e 6 (Média) & & $2,3 \%$ & & \\
\hline & 1 & LA1 & $79,4 \%$ & & \\
\hline & 4 & LA4 & $18,3 \%$ & & \\
\hline & 5 (Mista) & LA5 & $100 \%$ & & \\
\hline & 1 & ROR & $21 \%$ & & \\
\hline & 3 & FEP & $10,6 \%$ & & \\
\hline & 4 & CAF & $68,4 \%$ & & \\
\hline Cambuquira (MG) & 5 e 6 (Média) - Mista & REW, MAR & $100 \%$ & & \\
\hline Camouquira (IVIU) & 2 & SLI & $44,3 \%$ & & \\
\hline & 3 & FEP & $22,4 \%$ & & \\
\hline & $\stackrel{4}{5}$ e 6 (Média) - Mista & $\begin{array}{l}\text { CAF } \\
\text { REW, MAR }\end{array}$ & $\begin{array}{l}33,7 \% \\
100 \%\end{array}$ & & \\
\hline
\end{tabular}



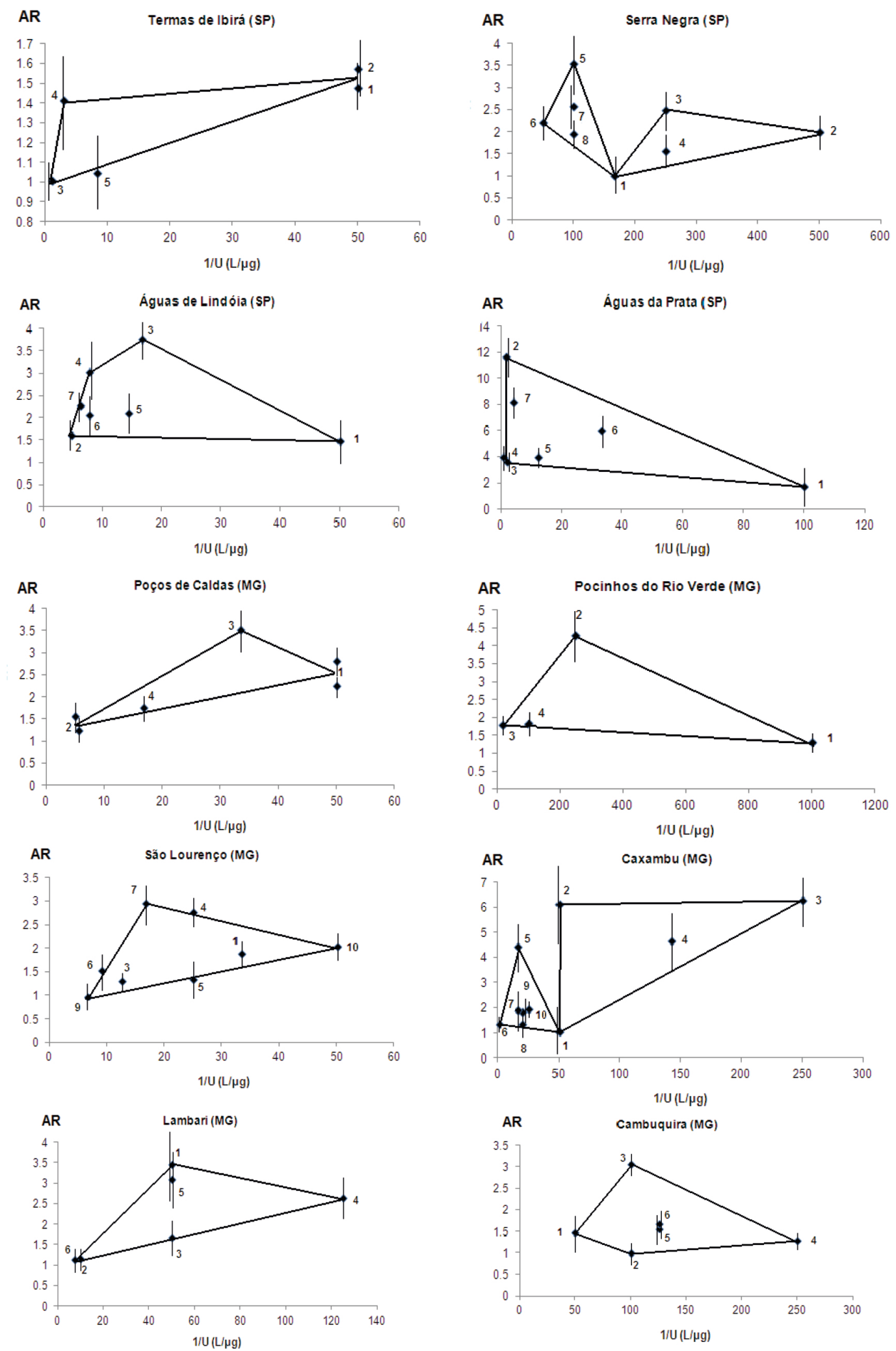

FIGURA 10 - Razão de atividade ${ }^{234} \mathrm{U} /{ }^{238} \mathrm{U}$ em função do inverso da concentração de urânio para águas subterrâneas de diferentes sistemas aquíferos nos estados de São Paulo e Minas Gerais. 
confiável. Os estudos geocronológicos envolvendo a datação das rochas tem utilizado distintos sistemas como o K-Ar, Ar-Ar, Rb-Sr, U-Th-Pb, Sm$\mathrm{Nd}$, Re-Os, etc., cada um com diferentes premissas que devem ser obedecidas para que a idade obtida possua significado para aquele contexto geológico estudado. Para os geocronólogos, a situação ideal consiste no emprego dos vários métodos disponíveis, visando encontrar resultados concordantes entre eles. Assim, este esforço deve ser dirigido ainda com mais ênfase no caso da datação das águas subterrâneas, pois, se trata de "matrizes" que exibem maiores dificuldades relativamente a minerais como biotita, hornblenda, monazita e zircão, comumente utilizados nos estudos geocronológicos. Longos tempos de residência de águas subterrâneas no SAG, a partir do uso dos isótopos de urânio ${ }^{238} \mathrm{U}$ e ${ }^{234} \mathrm{U}$, têm sido também determinados em investigações conduzidas com outros radionuclídeos de elevada meia vida, como é o caso do ${ }^{81} \mathrm{Kr}$ $(\sim 210 \mathrm{ka}) \mathrm{e}^{36} \mathrm{Cl}(\sim 301 \mathrm{ka})$. Porém, esses estudos não têm sido ainda realizados de maneira totalmente integrada, geralmente em virtude das limitações analíticas e custos envolvidos, dificultando a comprovação dos resultados obtidos com base nas hipóteses e premissas inerentes a cada método utilizado. Em adição ao uso cronológico dos resultados do desequilíbrio entre ${ }^{234} \mathrm{U}$ e ${ }^{238} \mathrm{U}$ nas águas subterrâneas, informações importantes têm sido também propiciadas no estudo dos processos de mistura das águas em vários sistemas aquíferos nos estados de São Paulo e Minas Gerais. Porém, similarmente ao que ocorre com a datação, há também a necessidade de se utilizar de maneira integrada outros traçadores naturais, a exemplo do esforço realizado para enfocar a presença nas águas dos isótopos estáveis de estrôncio ${ }^{86} \mathrm{Sr} \mathrm{e}{ }^{87} \mathrm{Sr}$. Isto certamente viabilizaria uma maior confiabilidade nos cenários propostos, contribuindo para uma melhor compreensão dos processos de circulação das águas e mais adequado gerenciamento dos recursos hídricos subterrâneos.

\section{AGRADECIMENTOS}

Os autores agradecem à FAPESP (Fundação de Amparo à Pesquisa do Estado de São Paulo), CNPq (Conselho Nacional de Desenvolvimento Científico e Tecnológico) e CAPES (Coordenação de Aperfeiçoamento de Pessoal de Nível Superior) do Brasil, bem como IAEA (International Atomic Energy Agency), Viena, Áustria, pelos auxílios à pesquisa e bolsas de estudo concedidas que possibilitaram o desenvolvimento de várias investiga- ções descritas neste trabalho. Agradecemos, também, aos revisores pelas contribuições oportunas e relevantes.

\section{REFERÊNCIAS BIBLIOGRÁFICAS}

ANDREWS, J.N.; KAY, R.L.F. 1978. The evolution of enhanced ${ }^{234} \mathrm{U} /{ }^{238} \mathrm{U}$ activity ratios for dissolved uranium and groundwater dating. In: INTERNATIONAL CONFERENCE ON GEOCHRONOLOGY, COSMOCHRONOLOGY AND ISOTOPE GEOLOGY, 4, Proceedings, USGS OpenFile Rep. 78-101: 11-13. https://doi. org/10.3133/ofr78701

ANDREWS，J.N.; KAY，R.L.F. 1982. ${ }^{234} \mathrm{U} /{ }^{238} \mathrm{U}$ activity ratios of dissolved uranium in groundwaters from a Jurassic limestone aquifer in England. Earth and Planetary Science Letters, 57: 139-151. https://doi. org/10.1016/0012-821X(82)90180-7

ANDREWS, J.N.; KAY, R.L.F. 1983. The U contents and ${ }^{234} \mathrm{U} /{ }^{238} \mathrm{U}$ activity ratios of dissolved uranium in groundwater from some Triassic sandstones in England. Chemical Geology, 41: 101-117. https://doi. org/10.1016/S0009-2541(83)80011-4

ANDREWS, J.N.; GILES, I.S.; KAY, R.L.F.; LEE, D.J.; OSMOND, J.K.; COWART, J.B.; FRITZ, P.; BARKER, J.F.; GALE, J. 1982. Radioelements, radiogenic helium and age relationships for groundwaters from granites at Stripa, Sweden. Geochimica et Cosmochimica Acta, 46: 1533-1543. https:// doi.org/10.1016/0016-7037(82)90312-X

BARANOV, V.I.; SURKOV, Y.A.; VILENSKII, V.D. 1958. Isotopic shifts in natural uranium compounds. Geochemistry, 5: 591-599.

BATEMAN, H. 1910. The solution of a system of differential equations occurring in the theory of radioactive transformations. Proceedings of the CambridgePhilosophicalSociety, 15(5): 423-427. https://www.biodiversitylibrary. org/item/97262\#page/487/mode/1up

BLANCHARD, R.L. 1965. ${ }^{234} \mathrm{U} /{ }^{238} \mathrm{U}$ ratios in coastal marine water and calcium carbonates. Journal of Geophysical Research, 70: 4055-4061. https://doi.org/10.1029/ JZ070i016p04055 
BOLTWOOD, B.B. 1908. Life of radium. American Journal of Science, 25: 493-506. https://doi.org/10.2475/ajs.s4-25.150.493

BONOTTO, D.M. 1993. Enhancement of Uranium 234 in spring waters of Águas da Prata (SP), Brazil. Water Resources Research, 29: 20412048. https://doi.org/10.1029/93WR00607

BONOTTO, D.M. 1994. Utilização de modelo isotópico de urânio no estudo de aqüíferos do Morro do Ferro, Poços de Caldas (MG). Revista Brasileira de Geociências, 24(1): 5259. http://bjg.siteoficial.ws/1994/n.1/6.pdf

BONOTTO, D.M. 1998. Nitrification processes in groundwaters evidenced by modification on the $U$ contents and ${ }^{234} U /{ }^{238} U$ activity ratios. In: J-L. USÓ, C.A. BREBBIA \& H. POWER (ed.) Ecosystems and Sustainable Development. Southampton, WIT Press, p. 193-202.

BONOTTO, D.M. 2005. The U-isotopes modeling in aquifers from Poços de Caldas plateau, Brazil. Environmental Geology, 48: 507-523. http://dx.doi.org/10.1007/s00254-005-1301-7

BONOTTO, D.M. 2006. Hydro(radio)chemical relationships in the giant Guarani aquifer, Brazil. Journal of Hydrology, 323: 353-386. $\quad \mathrm{http}: / / \mathrm{dx}$. doi.org/10.1016/j. jhydrol.2005.09.007

BONOTTO, D.M. 2013. A comparative study of aquifer systems occurring at the Paraná sedimentary basin, Brazil: U-isotopes contribution. Environmental Earth Sciences, 68: 1405-1418. http://dx.doi.org/10.1007/ s12665-012-1838-1

BONOTTO, D.M. 2016. Hydrogeochemical study of spas groundwaters from southeast Brazil. Journal of Geochemical Exploration, 169: 60-72. http://dx.doi.org/10.1016/j. gexplo.2016.07.016

BONOTTO, D.M. 2017. The dissolved uranium concentration and ${ }^{234} \mathrm{U} /{ }^{238} \mathrm{U}$ activity ratio in groundwaters from spas of southeastern Brazil. Journal of Environmental Radioactivity, 166: 142-151. http://dx.doi. org/10.1016/j.jenvrad.2016.03.009

BONOTTO, D.M.; ANDREWS, J.N. 1993. The mechanism of ${ }^{234} \mathrm{U} /{ }^{238} \mathrm{U}$ activity ratio enhancement in karstic limestone aquifer. Chemical Geology 103: 193-206. http:// dx.doi.org/10.1016/0009-2541(93)90301-X

BONOTTO, D.M.; ANDREWS, J.N. 2000. The transfer of uranium isotopes ${ }^{234} \mathrm{U}$ and ${ }^{238} \mathrm{U}$ to the waters interacting with carbonates from Mendip Hills area (England). Applied Radiation and Isotopes, 52: 965-983. http:// dx.doi.org/10.1016/S0969-8043(99)00151-7

BONOTTO, D.M.; ANDREWS, J.N.; DARBYSHIRE, D.P.F. 2001. A laboratory study of the transfer of ${ }^{234} \mathrm{U}$ and ${ }^{238} \mathrm{U}$ during water-rock interactions in the Carnmenellis granite (Cornwall, England) and implications for the interpretation of field data. Applied Radiation and Isotopes, 54: 977-994. https:// doi.org/10.1016/S0969-8043(00)00338-9

CHAPMAN, N.A.; McKINLEY, I.G.; SHEA, M.E.; SMELLIE, J.A.T. 1993. The Poços de Caldas Project: Natural Analogues of Processes in a Radioactive Waste Repository. Elsevier, Amsterdam. https://doi.org/10.1016/C20090-10213-1

CHATAM, J.R.; WANTY, R.B.; LANGMUIR, D. 1981. Ground-water prospecting for sandstone-type uranium deposits: the merits of mineral-solution equilibria versus single element tracer methods. National uranium resource evaluation. U.S. Department of Energy, 168 p. https://inis.iaea.org/search/ search.aspx?orig_q=reportnumber:\%22GJ BX--404-81\%22

CHERDYNTSEV, V.V. 1969. Uranium-234. Wiener Brindery Ltd., Jerusalem, 234 p.

CHERDYNTSEV, V.V.; KAZACHEVSKII, I.V.; KUZ'MINA, E.A. 1955. Dating of Pleistocene carbonate formation by thorium and uranium isotopes. Geochemistry International, 3: 794-801.

COWAN, G.A. 1976. A natural fission reactor. Scientific American, 235: 36-47. https://doi. org/10.1038/scientificamerican0776-36

COWART, J. B. 1980. The relationship of uranium isotopes to oxidation/reduction in the Edwards Carbonate Aquifer of Texas. Earth and Planetary Science Letters, 48: 
277-283. $\quad$ https://doi.org/10.1016/0012821X(80)90191-0

COWART, J.B.; OSMOND, J.K. 1974. ${ }^{234} \mathrm{U}$ and ${ }^{238} \mathrm{U}$ in the Carrizo sandstone aquifer of south Texas. In: IAEA(International Atomic Energy Agency), SYMPOSIUM ON ISOTOPE TECHNIQUES IN GROUNDWATER HYDROLOGY, 4, Vienna, Proceedings, 2: 131-149. https://inis.iaea.org/search/search. aspx?orig_q=RN:38048698

COWART, J.B.; OSMOND, J.K. 1977. Uranium isotopes in groundwater: their use in prospecting for sandstone-type uranium deposits. Journal of Geochemical Exploration, 8: 365-379. https://doi. org/10.1016/0375-6742(77)90062-0

FRÖHLICH, K.; GELLERMANN, R. 1987. On the potential use of uranium isotopes for groundwater dating. Isotope Geoscience, 65: 67-77. https://doi.org/10.1016/01689622(87)90063-7

GEIGER, H.; NUTTALL, J.M. 1911. The Ranges of the $\alpha$-Particles from Various Radioactive Substances and a Relation Between Ranger and Period of Transformation. The Philosophical Magazine, 22: 613. https://doi. org/10.1080/14786441008637156

GEIGER, H.; RUTHERFORD, E. 1910. The number of alpha particles emitted by uranium and thorium and by uranium minerals. The Philosophical Magazine, 20: 691 -698. http:// dx.doi.org/10.1080/14786441008636954

GILBOA, Y.; MERO, F.; MARIANO, I.B. 1976. The Botucatu aquifer of South America, model of an untapped continental aquifer. Journal of Hydrology, 29(1): 165-179. https:// doi.org/10.1016/0022-1694(76)90012-3

GOMES, F.V.M. 1978. Aplicação dos isótopos do urânio como traçadores de água subterrânea do Bambuí-Bahia. Universidade Federal da Bahia, Salvador, Dissertação de Mestrado, 69 p. https://inis.iaea. org/collection/NCLCollectionStore/_ Public/12/573/12573331.pdf?r=1\&r=1

HILL, C.R.; CROOKALL, J.O. 1963. Natural occurrence of ${ }^{234} \mathrm{U}$-enriched uranium. Journal of Geophysical Research, 68: 2358. https:// doi.org/10.1029/JZ068i008p02358

IVANOVICH, M.; HARMON, R.S. 1982. Uranium series disequilibrium - Applications to environmental problems. Clarendon Press, Oxford, $571 \mathrm{p}$.

IVANOVICH, M.; FRÖHLICH, K.; HENDRY, M.J. 1991. Uranium-series radionuclides in fluids and solids, Milk River aquifer, Alberta, Canada. Applied Geochemistry, 6: 405-418. https://doi.org/10.1016/08832927(91)90040-V

KAUFMAN, A.; BROECKER, W. 1965. Comparison of ${ }^{230} \mathrm{Th}$ and ${ }^{14} \mathrm{C}$ ages for carbonate materials from lakes Lahontan and Bonneville. Journal of Geophysical Research, 70: 4039-4054. https://doi. org/10.1029/JZ070i016p04039

KAUFMAN, A.; RYDELL, H.S.; OSMOND, J.H. 1969. ${ }^{234} \mathrm{U} /{ }^{238} \mathrm{U}$ disequilibrium as an aid to hydrologic study of the Floridan aquifer. Journal of. Hydrology, 9: 374-386. https:// doi.org/10.1016/0022-1694(69)90085-7

KIGOSHI, K. 1971. Alpha-recoil 234Th: dissolution into water and the $234 \mathrm{U} / 238 \mathrm{U}$ disequilibrium in nature. Science, 173: 47-48. https://doi.org/10.1126/science.173.3991.47

KIMMELMANN, A.; FORSTER, M.; COELHO, R. 1995. Environmental isotope and hydrogeochemical investigation of Bauru and Botucatu aquifers, Paraná Basin, Brazil. In: IAEA (International Atomic Energy Agency), Isotope Hydrology Investigations in Latin America, 1994. Impresso por OIEA, Austria, p. 57-74. https://inis.iaea. org/collection/NCLCollectionStore/_ Public/27/018/27018923.pdf?r=1

KOIDE, M., GOLDBERG, E.D. 1965. Uranium-234/uranium-238 ratios in sea water. In: M. Sears (ed.) Progress in Oceanography, v. 3, New York, Pergamon Press, p. 173-177. https://doi. org/10.1016/0079-6611(65)90016-9

KRONFELD, J. 1974. Uranium deposition and Th234 alpha-recoil: an explanation for extreme U-234/U-238 fractionation within the Trinity aquifer. Earth and Planetary Science Letters, 
21: 327-330. https://doi.org/10.1016/0012$821 \mathrm{X}(74) 90169-1$

KRONFELD, J.; ADAMS, J.A.S. 1974. Hydrologic investigations of the groundwaters of central Texas using U-234/U-238 disequilibrium. Journal of. Hydrology, 22: 77-88. https://doi. org/10.1016/0022-1694(74)90097-3

KRONFELD, J.; GRADSZTAJN, E.; MUELLER, H.W.; RADIN, J.; YANIV, A.; ZACH, R. 1975. Excess ${ }^{234} \mathrm{U}$ : an aging effect in confined waters. Earth and Planetary Science Letters, 27(2): 342-345. https://doi. org/10.1016/0012-821X(75)90046-1

KU, T.L. 1965. An evaluation of the ${ }^{234} \mathrm{U} / 238 \mathrm{U}$ method as a tool for dating pelagic sediments. Journal of Geophysical Research, 70: 3457-3474. https://doi.org/10.1029/ JZ070i014p03457

KU, T.L. 1976. The uranium-series methods of age determination. Annual. Review of Earth Planetary Sciences, 4: 347-379. https://doi. org/10.1146/annurev.ea.04.050176.002023

MANCINI, L.H. 2002. Migração de Ra-226 e Ra228 nas águas superficiais e subterrâneas do Barreiro de Araxá (MG). Instituto de Geociências e Ciências Exatas, Universidade Estadual Paulista Júlio de Mesquita Filho, Rio Claro, Tese de Doutorado (Geociências e Meio Ambiente), 197 p. https://repositorio. unesp.br/handle/11449/102903

MANCINI, L.H.; BONOTTO, D.M. 2015. Uranium isotopes in ground and surface waters of Barreiro, Araxá, Minas Gerais State, Brazil. In: J. R. NELSON (ed) Uranium: sources, exposure and environmental effects. New York, Nova Science Publishers, p. 157-170.

MIYAKE, Y.; SUGIMURA, Y.; UCHIDA, T. 1966. Ratio ${ }^{234} \mathrm{U} / 238 \mathrm{U}$ and the uranium concentration in seawater in the western North Pacific. Journal of Geophysical Research, 71: 3083-3087. https://doi.org/10.1029/ JZ071i012p03083

MOORE, W.S. 1967. Amazon and Mississippi river concentrations of uranium, thorium and radium isotopes. Earth and Planetary Science Letters, 2: 231-234. https://doi. org/10.1016/0012-821X(67)90134-3
MOREIRA-NORDEMANN, L.M. 1977. Etude de la vitesse d'alteration des roches au moyen de l'uranium utilise comme traceur naturel. Application a deux bassins du nordest $d u$ Bresil. Université Pierre et Marie Curie, Paris, Thèse de Doctorat d'État, 162 p.

NIER, A.O. 1939. The isotopic constitution of uranium and the half - lives of the uranium isotopes. Physics Review, 55: 150153. https://doi.org/10.1103/PhysRev.55.150

OSMOND, J.K.; COWART, J.B. 1976. The theory and uses of natural uranium isotopic variations in hydrology. Atomic Energy Review, 14: 621-679. https://inis.iaea.org/ search/search.aspx?orig_q=RN:8327949

OSMOND, J.K.; CARPENTER, J.R.; WINDOW, H.L. $1965 .{ }^{230} \mathrm{Th} /{ }^{234} \mathrm{U}$ age of the Pleistocene corals and oolites of Florida. Journal of Geophysical Research, 70: 1843- 1847. https://doi.org/10.1029/JZ070i008p01843

OSMOND, J.K.; RYDELL, H.S.; KAUFMAN, M.I. 1968. Uranium disequilibruim in groundwater: an isotope dilution approach in hydrologic investigations. Science, 162: 997-999. https://doi.org/10.1126/ science.162.3857.997

OSMOND, J.K.; KAUFMAN, M.I.; COWART, J.B. 1974. Mixing volume calculations, sources and aging trends of Floridan aquifer water by uranium isotopic methods. Geochimica et Cosmochimica Acta, 38: 1083-1100. https://doi.org/10.1016/00167037(74)90006-4

REBOUÇAS, A.C. Recursos hídricos subterrâneos da bacia do Paraná - analise de préviabilidade. 1976. Instituto de Geociências, Universidade de São Paulo, São Paulo, Tese de Livre-Docência, 143 p. https://teses.usp. $\mathrm{br} /$ teses/disponiveis/livredocencia/44/tde02062014-141431/pt-br.php

REYES, E. 2009. Comportamento dos radioisótopos ${ }^{238} \mathrm{U},{ }^{234} \mathrm{U}, \quad{ }^{226} \mathrm{Ra},{ }^{228} \mathrm{Ra} \quad \mathrm{e}$ da razão isotópica ${ }^{87}{ }^{8 r}{ }^{86} \mathrm{Sr}$ em águas subterrâneas extraídas de corpos graníticos fraturados da Suite Intrusiva de Itu (SP). Instituto de Astronomia, Geofísica e Ciências Atmosféricas, Universidade de São Paulo, São Paulo, Tese de Doutorado (Geofísica), 
204 p. https://www.iag.usp.br/pos/sites/ default/files/Reyes_ERIKA_Doutorado.pdf

SCOTT, M.R. 1968. Thorium and uranium concentrations and isotope ratios in river sediments. Earth and Planetary Science Letters, 4: 245-252. https://doi. org/10.1016/0012-821X(68)90042-3

SILVA, H.S.B. 2011. Estudo em laboratório da dinâmica dos isótopos de urânio no processo de interação rocha-água em granitóides do Complexo Itu (SP). Instituto de Astronomia, Geofísica e Ciências Atmosféricas, Universidade de São Paulo, São Paulo, Dissertação de Mestrado (Geofísica), 77 p. https://www.iag.usp.br/pos/sites/default/ files/d_helen_s_b_silva_corrigida.pdf

SILVA, M.L.; BONOTTO, D.M. 2015. Uranium isotopes in groundwater occurring at Amazonas State, Brazil. Applied Radiation and Isotopes, 97: 24-33. https://doi. org/10.1016/j.apradiso.2014.12.012

SILVEIRA, E.G.; BONOTTO, D.M. 1995. Comportamento hidrogeoquímico dos isótopos de urânio em Águas de Lindóia (SP), Brasil. Revista Brasileira de Geociências, 25:
165-172. http://bjg.siteoficial.ws/1995/n.3/2. pdf

SODDY, F. 1923. The origins of the conception of isotopes. Nature, 112: 208. https://doi. org/10.1038/112208a0

SOMAYAJULU, B.L.K.; CHURCH, T.M. 1973. Radium, thorium and uranium isotopes in the interstitial water from the Pacific Ocean sediment. Journal of Geophysical Research, 78: 4529-4531. https://doi.org/10.1029/ JC078i021p04529

THURBER, D.L. 1962. Anomalous ${ }^{234} \mathrm{U} / 238 \mathrm{U}$ in nature. Journal of Geophysical Research, 67: 4518-4520. https://doi.org/10.1029/ JZ067i011p04518

WARKSHAL, E.; YARON, F. 1974. ${ }^{234} \mathrm{U} /{ }^{238} \mathrm{U}$ disequilibrium in waters of the Judea Group (Cenomanian-Turonian) aquifer in Galilee, northern Israel. In: IAEA (International Atomic Energy Agency), SYMPOSIUM ON ISOTOPE TECHNIQUES IN GROUNDWATER HYDROLOGY, Vienna, 4, Proceedings, 2: 151-177. https:// inis.iaea.org/search/search.aspx?orig_ $\mathrm{q}=\mathrm{RN}: 38048699$

\section{Endereço dos autores:}

Luís Henrique Mancini - Laboratório de Estudos Geocronológicos, Geodinâmicos e Ambientais, Instituto de Geociências, Universidade de Brasília, Campus Darcy Ribeiro, CEP 70910-900, Brasília, DF, Brasil. E-mail:1hmunb@gmail.com

Daniel Marcos Bonotto - Departamento de Geologia, Instituto de Geociências e Ciências Exatas, Universidade Estadual Paulista/UNESP, Av. 24-A, 1515, C.P. 178, Bela Vista, CEP 13506-900, Rio Claro, São Paulo, Brasil.E-mail: daniel.bonotto@unesp.br

Artigo submetido em 23 de dezembro de 2020, aceito em 1 de março de 2021. 